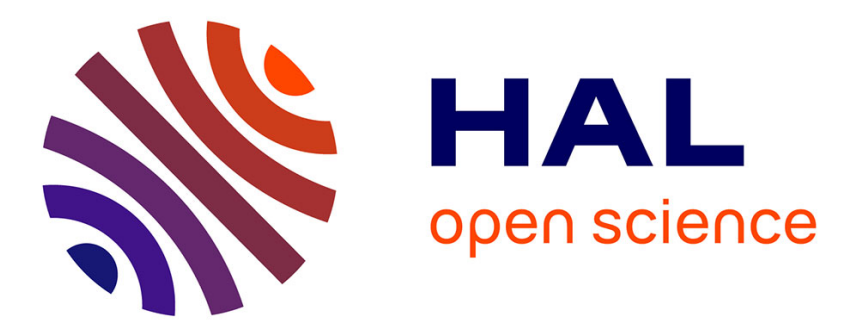

\title{
Epitope load identifies kidney transplant recipients at risk of allosensitization following minimization of immunosuppression
}

Renaud Snanoudj, Nassim Kamar, Elisabeth Cassuto, Sophie Caillard, Marie Metzger, Pierre Merville, Antoine Thierry, Isabelle Jollet, Philippe Grimbert, Dany Anglicheau, et al.

\section{To cite this version:}

Renaud Snanoudj, Nassim Kamar, Elisabeth Cassuto, Sophie Caillard, Marie Metzger, et al.. Epitope load identifies kidney transplant recipients at risk of allosensitization following minimization of immunosuppression. Kidney International, 2019, 95 (6), pp.1471-1485. 10.1016/j.kint.2018.12.029 . hal-02190537

\section{HAL Id: hal-02190537 \\ https://hal.univ-brest.fr/hal-02190537}

Submitted on 25 Oct 2021

HAL is a multi-disciplinary open access archive for the deposit and dissemination of scientific research documents, whether they are published or not. The documents may come from teaching and research institutions in France or abroad, or from public or private research centers.
L'archive ouverte pluridisciplinaire HAL, est destinée au dépôt et à la diffusion de documents scientifiques de niveau recherche, publiés ou non, émanant des établissements d'enseignement et de recherche français ou étrangers, des laboratoires publics ou privés.

\section{(ㄷ)(1) $\$$}

Distributed under a Creative Commons Attribution - NonCommerciall 4.0 International 
[QUERY TO AUTHOR: title and abstract rewritten by Editorial Office - not subject to change] Epitope load identifies kidney transplant recipients at risk of allosensitization following minimization of immunosuppression

Renaud Snanoudj ${ }^{1,2}$ MD PhD, Nassim Kamar $^{3}$ MD PhD, Elisabeth Cassuto ${ }^{4}$ MD, Sophie Caillard $^{5} \mathrm{MD} \mathrm{PhD}$, Marie Metzger ${ }^{2} \mathrm{PhD}$, Pierre Merville ${ }^{6} \mathrm{MD} \mathrm{PhD}$, Antoine Thierry ${ }^{7} \mathrm{MD}$ $\mathrm{PhD}$, Isabelle Jollet ${ }^{8} \mathrm{MD}$, Philippe Grimbert ${ }^{9} \mathrm{MD} \mathrm{PhD}$, Dany Anglicheau ${ }^{10} \mathrm{MD} \mathrm{PhD}$, Marc Hazzan $^{11}$ MD PhD, Gabriel Choukroun ${ }^{12}$ MD PhD, Bruno Hurault De Ligny ${ }^{13}$ MD PhD, Bénedicte Janbon ${ }^{14} \mathrm{MD}$, Vincent Vuiblet ${ }^{15} \mathrm{MD}$, Anne Devys ${ }^{16} \mathrm{MD}$, Yann Le Meur ${ }^{17} \mathrm{MD}$ $\mathrm{PhD}$, Michel Delahousse ${ }^{1} \mathrm{MD}$, Emmanuel Morelon ${ }^{18} \mathrm{MD} \mathrm{PhD}$, Elodie Bailly ${ }^{19}$, Sophie Girerd $^{20}$ MD MSc, Kahina Amokrane ${ }^{21}$ MD, Christophe Legendre ${ }^{10}$ MD, Alexandre Hertig ${ }^{22}$ MD PhD, Eric Rondeau ${ }^{22}$ MD PhD, Jean-Luc Taupin ${ }^{21}$ PharmD, PhD

1: Service de Néphrologie, Hémodialyse et Transplantation Rénale, Hôpital Foch, Suresnes, France

2 : CESP, INSERM, Université Paris-Sud, UVSQ, Université Paris-Saclay, Villejuif, France 3: Service de Néphrologie et Transplantation d'organe. CHU Rangueil, Toulouse, France 4: Service de Néphrologie, Hôpital Pasteur, CHU de Nice, France

5: Service de Néphrologie et transplantation, CHU de Strasbourg, France 6: Service de Néphrologie et Transplantation, Hôpital Pellegrin, Bordeaux, France

7: Service de Néphrologie et Transplantation, CHU de Poitiers, France

8: Laboratoire HLA, EFS de Poitiers, France

9: Service de Néphrologie et Transplantation, Hôpital Henri Mondor, Créteil, France 10 : Service de Transplantation et Néphrologie, Hôpital Necker, Assistance Publique Hôpitaux de Paris, France

11: Service de Néphrologie, Hôpital Claude Huriez, CHRU de Lille, France

12: Service de Néphrologie, CHU Amiens-Picardie, Amiens, France

13: Service de Néphrologie et Transplantation, CHU de Caen, France

14: Service de Néphrologie et Transplantation, CHU de Grenoble, France

15: Service de Néphrologie, Hôpital Maison Blanche, Reims, France

16: Etablissement français du sang - Centre Pays de Loire, Angers, France

17: Service de Néphrologie, CHU de Brest, France 
18: Service de Transplantation, Néphrologie et Immunologie Clinique, Hôpital Edouard Herriot, Hospices Civils de Lyon, France

19: Service de Néphrologie, Hôpital Bretonneau, CHU de Tours, France

20: Service de Néphrologie, CHU Nancy Brabois, Nancy, France

21: Laboratoire d'Immunologie et Histocompatibilité Hôpital Saint-Louis, Paris, France and INSERM UMRs 1160, Institut Universitaire d'Hématologie, Université Paris Diderot. 21: Service de Néphrologie et Transplantation, Hôpital Tenon, Paris, France

Running title: Epitope load and de novo DSA

Word count: Text $\quad 4000$

Corresponding author:

Dr Renaud Snanoudj

Service de Néphrologie, Hémodialyse et Transplantation rénale,

Hôpital FOCH

40 rue WORTH

92151 SURESNES CEDEX

e-mail: r.snanoudj@hopital-foch.com

Tel 0033144495432

Fax 0033144495430 


\begin{abstract}
HLA mismatching and minimization of immunosuppression are two major risk factors for the development of de novo donor specific antibodies, which is associated with reduced kidney graft survival. Antibodies do not recognize whole HLA antigens but rather individual epitopes, which are short sequences of amino acids in accessible positions. However, compatibility is still assessed by the simple count of mismatched HLA antigens. We hypothesized that the number of mismatched epitopes, or ("epitope load") would identify patients at the highest risk of developing donor specific antibodies following minimization of immunosuppression. We determined epitope load in 89 clinical trial participants who converted from cyclosporine to everolimus 3 months after kidney transplantation. Twentynine participants $(32.6 \%)$ developed de novo donor specific antibodies. Compared to the number of HLA mismatches, epitope load was more strongly associated with the development of donor specific antibodies. Participants with an epitope load greater than 27 had a 12 -fold relative risk of developing donor-specific antibodies compared to those with an epitope load below that threshold. Using that threshold, epitope load would have missed only one participant who subsequently developed donor specific antibodies, compared to 8 missed cases based on a 6-antigen mismatch. DQ7 was the most frequent antigenic target of donor specific antibodies in our population, and some DQ7 epitopes appeared to be more frequently involved than others. Assessing epitope load before minimizing immunosuppression may be a more efficient tool to identify patients at the highest risk of allosensitization.
\end{abstract}

\title{
Keywords
}

Acute rejection; kidney transplantation, antibody-mediated rejection; HLA mismatching; epitopes; immunosuppression minimization 


\section{Introduction}

Numerous reports have shown a significant influence of the number of HLA mismatches on kidney graft survival ${ }^{1-4}$, although this concept has also been challenged ${ }^{5}$.

The recent advent of solid phase assays detecting anti-HLA antibodies has shed light on how HLA matching influences the occurrence of de novo donor specific antibodies (dnDSA). Indeed, class II HLA matching and inadequate immunosuppression are two independently recognized risk factors for dnDSA development ${ }^{6,7}$. Moreover, antibodymediated rejection (ABMR) due to dnDSA is associated with a $40 \%$ reduction in 10 years graft survival ${ }^{6}$ and appears as a major cause of late allograft loss ${ }^{8-12}$. Despite the worldwide use of allocation algorithms taking into account HLA matching, approximately $10-15 \%$ of patients still develop dnDSA within an average of six years post-transplant $6,13,14$, questioning the reliability of current typing for minimizing the risk of allosensitization. Donor/recipient HLA compatibility has always been assessed by a simple count of HLA mismatched antigens, i.e. at the "serologic" level although typing has been more and more performed using molecular techniques for at least a decade. Yet, anti-HLA antibodies do not recognize whole HLA antigens but rather epitopes, i.e. short polymorphic sequences of amino acids in antibody-accessible positions ${ }^{15,16}$. Two approaches are used to identify HLA allogenic epitopes. The HLAMatchmaker algorithm developed by Duquesnoy relies on how immunoglobulin paratopes bind to protein epitopes localized on the molecule surface, to identify theoretical HLA epitopes ${ }^{17,18}$. The empirical approach by Terasaki verifies the existence of epitopes through the ability of antibodies to bind all alleles that share the same amino acid sequences exposed on the HLA molecule ${ }^{16,19}$. HLAMatchmaker is updated with the epitope registry (www.epregistry.com) and references those verified epitopes, referred to in this manuscript as "antibody-verified", besides the non-verified epitopes ${ }^{20}$. HLAMatchmaker compares donor and recipient HLA molecules at the structural level to infer the number of mismatched epitopes called the epitope load ${ }^{17}$. Using HLAMatchmaker, Wiebe et al. showed that class II epitope load was associated with the long-term risk of developing dnDSA 21 .

In our study, we hypothesized that preliminary determination of epitope load, in the daily clinical practice, could be a reliable and easy-to-use tool to identify patients at the highest risk of dnDSA development when a minimization of immunosuppression is 
envisioned. We tested this hypothesis in patients who were randomized for switching from cyclosporine (CsA) to everolimus three months post-transplantation ${ }^{22}$, a modification associated with a high incidence of early dnDSA (up to $27 \%$ at one year) and $\mathrm{ABMR}$, and considered as a minimization of immunosuppression ${ }^{23}$. We also qualitatively determined whether some mismatched epitopes were more immunogenic than others, i.e., more prone to trigger dnDSA.

\section{Results}

\section{Characteristics of the study population and clinical course of transplantations.}

The patients who were switched at three months post-transplantation from CsA to everolimus $(n=89)$ all received a first kidney transplant (Table1). None had DSA either at transplantation or at conversion. After a mean follow-up of $83.8 \pm 27.9$ months, 29 patients (32.6\%: 25 before and 4 after month-12 post-transplantation) developed dnDSA, mainly against class II antigens (Figure 1). Twenty patients (22.5\%) experienced a T-cell mediated rejection (TCMR) and five had a clinical episode of antibody-mediated rejection (ABMR) during the first year, all after conversion to everolimus [8 to 12 months post-transplantation]. Four other patients exhibited significant microvascular inflammation $(g+p t c \geq 2)$ on the systematic month-12 biopsy. Five patients lost their graft due to TCMR, from 6 to 13 months after transplantation, with three patients presenting concomitant dnDSA and microvascular inflammation. Regarding the impact of dnDSA in the everolimus arm, patient survival was similar in patients with or without dnDSA (Figure 2A), whereas death-censored graft survival was significantly lower in patients with dnDSA: $62.5 \%$ versus $93.1 \%$ at 8 years, $p=0.0005$ (Figure $2 B$ ). Graft survival was similar in the two arms of treatment (Figure 2C). Renal function declined from month-3 in patients who developed dnDSA in the everolimus arm, but was similar in the two arms of treatment (Figure S1). 


\section{Evaluation of HLA compatibility with antigenic, allelic and epitopic mismatches}

Table S1 shows the different levels of mismatches in the two arms of treatment, class II allelic and antibody-verified epitopic mismatches being higher in the everolimus arm. Table 2 focuses on the distribution of the three levels of mismatches for the patients of the everolimus arm. Figure 3 shows how these values overlap, even if they are clearly correlated. The number of antigenic (Figure 3A/3B) and allelic (Figure 3D/3F) mismatches may under- or overestimate the level of epitopic incompatibility. The correlation of epitopic mismatches with allelic mismatches is not better than with antigenic mismatches. Donor/recipient pairs considered HLA identical at the antigen level may in fact present allelic (Figures 3C/3E) and epitopic (Figures 3A/3B) mismatches. Figure S2 shows that correlation with antibody-verified epitopes is even lower than with the total number of epitopes.

Figure 4A illustrates for two patients how epitope load may be more informative than antigenic mismatches. In both cases, there were one DR and one DQ mismatched antigens and four mismatched alleles (DRB1, DRB3/4/5, DQB1 and DQA1). The epitope load was low in the first case (8 DR - including one antibody-verified-and 8 DQ epitopic mismatches), but higher in the second (20 DR and 28 DQ epitopic mismatches with a high proportion of antibody-verified epitopes). Only the second patient developed DR and DQ dnDSA. Then, a given number of antigenic or allelic mismatches may underlie very different levels of epitopic mismatching.

Moreover, given antigenic mismatches may be associated with distinct epitope loads depending on structural differences between donor and recipient HLA. For example (Figure 4B), a DQ7 antigenic mismatch represents 1 epitopic mismatch for a DQ6/DQ9 recipient (panel-1), 8 mismatches for a DQ2/DQ4 recipient (panel-2), and 16 mismatches for a DQ2/DQ2 recipient (panel-3). The DQ2 homozygous patient can "see" more epitopic mismatches than the heterozygous DQ2/DQ4 recipient because the epitopes shared by DQ4 and DQ7 are not considered as "self". Regarding anti-DQ7 allosensitization, only the last two recipients developed a dnDSA. 


\section{Factors associated with the development of dnDSA}

Patients with or without dnDSA had similar baseline characteristics (Table 1) except for age, and similar CsA (until month-3), everolimus (after month-3) and mycophenolic acid exposure (Table 3). Among the 89 patients, 21 experienced a premature discontinuation of everolimus (replaced by a CNI), after $1.9 \pm 1.3$ month of treatment but the frequency of dnDSA was similar compared with that of patients maintained on everolimus until month-12 (see Figure S3 for details on everolimus and rejections). Patients with dnDSA experienced more TCMR but the difference was not significant (Table 1).

Table 4 summarizes antigenic, allelic and epitopic mismatches in relation with the occurrence of dnDSA. Whatever their class, dnDSA were more strongly associated with the number of antibody-verified epitopic mismatches than with the number of total epitopic mismatches, than with the number of antigenic mismatches. The number of allelic mismatches was only associated with class I or II DSA and with class II DSA, but at a lower level. The occurrence of DR dnDSA was only associated with the number of antibody-verified epitopes.

We performed a ROC curve analysis to determine the mismatch thresholds that best predicted the development of dnDSA for the different loci (Table 5). For class I or II, class I, class II and DQ DSA, AUC were always greater with antibody-verified and then total epitopic mismatches than with antigenic and allelic mismatches mismatches. As compared to the AUC of antigenic mismatches, statistical significance was not reached for any mismatches types. To note, the AUC of antibody-verified epitopic mismatches was nearly significant regarding the occurrence of dnDSA (class I or II) $(p=0.06)$. The global relative risk for developing any dnDSA, regardless of class, was 2.0 for more than 6 antigenic mismatches, 8.0 for more than 15 verified epitopes and 12.2 for more than 27 total epitopic mismatches. In identifying patients who developed class I or II dnDSA, using the above-mentioned thresholds, antigenic mismatches would have missed 8 patients compared with only one for epitope load (Figure 5). The same results were obtained in the transplantations for which a donor and recipient allelic typing could be performed. 
Multivariate logistic regressions (Table 6) showed that epitope load, as a continuous variable, was the only factor independently associated with the risk of developing class I or II dnDSA.

Interestingly, there was no correlation between the occurrence of ABMR or TCMR, or isolated microvascular inflammation on month-12 biopsy, and any level of mismatches (Table S2).

Regarding the influence of immunosuppression, occurrence of $\operatorname{dnDSA}$ was delayed and less frequent in the cyclosporine group than in the everolimus arm. Indeed, 16 patients (18.6\%), 3 before and 13 after month-12, developed dnDSA whereas 29 patients (32.6\%, $\mathrm{p}=0.034$ ) developed DSA in the everolimus group. Five-year graft survival without DSA was $85 \%$ in the cyclosporine group versus $69.1 \%$ in the everolimus group $(\mathrm{p}=0.026$, Figure 6). Under cyclosporine, according to ROC curve analysis, the thresholds associated with the occurrence of class I or II dnDSA were lower: 5 (antigenic mismatches), 6 (allelic mismatches), 22 (total epitopes) and 16 (antibody-verified epitopes). The antibody-verified epitope load was similar in patients in the everolimus arm not developing dnDSA and in the cyclosporine group (14.8 \pm 7.0 versus $15.2 \pm 6.6$, $\mathrm{p}=0.7)$. However, the proportion of patients who developed dnDSA with an epitope load above the threshold which is similar (15 for everolimus, 16 for cyclosporine) is higher in the everolimus arm: $48.2 \%$ versus $26.1 \%, \mathrm{p}=0.02$.

\section{Identification of the most immunogenic epitopes}

DQ7 was the most frequent antigenic target of dnDSA. Considering the 23 DQ7negative patients who received a DQ7positive graft, the number of mismatched DQ7 epitopes was significantly higher in the 11 patients (47.8\%) who developed a DQ7 dnDSA (Figure 7A and 7B). Qualitatively, several DQ7 epitopes were significantly more often mismatched when the recipients developed anti-DQ7 dnDSA (Odds-Ratio 11.6 to 23.9), such as 55PP and 77T (antibody-verified) or 37YA, 70RT and 74EL (non-verified). Others were mismatched either with a similar frequency regardless of the development of anti-DQ7 dnDSA (52PL, 140T, 182N, 56PD, 45EV, 14AM, 26Y) (Figure 7C), or in too few cases (0 to 3 cases) for a statistical comparison.

We verified that anti-DQ7 dnDSA often recognized these mismatched epitopes by analyzing serum reactivity using HLAMatchmaker (Table 7). In 6 of the 10 cases we 
could analyze, the targeted epitope was 55PP or 77T, two antibody-verified epitopes that were mismatched significantly more often (Figure 7).

\section{Discussion}

In this study, we took advantage of the high incidence of dnDSA after switching from CsA to everolimus to show that the epitope load was a more reliable method for assessing HLA compatibility than the mere counting of antigenic mismatches.

In two recent studies, the number of HLA antigenic mismatches was a strong predictor of long-term graft survival ${ }^{3,4}$. HLA compatibility is involved in the allogenic immune response, and especially in class II dnDSA development 6,10, critically associated with worse post-transplant outcomes ${ }^{8-12}$. Given the difficulty of controlling other factors, such as poor adherence, it is important to identify a priori the patients at the highest risk of post-transplant sensitization.

HLA matching has been traditionally based on serologically defined HLA antigens, although anti-HLA antibodies react against specific epitopes and not against the antigen as a whole ${ }^{15,16}$. Epitopes in an HLA molecule can be deduced from allelic typing but not from serologic typing. Therefore, simply counting antigenic mismatches does not allow for the reliable identification of mismatched epitopes.

Molecular techniques for typing and crystallographic studies ${ }^{24,25}$ have provided a better understanding of the central role of epitopes as the targets of alloantibodies. HLA antigens are in fact groups of close alleles with minor sequence differences resulting in the expression of mismatched epitopes that can even stimulate the synthesis of alloantibodies within the same allelic group.

We compared the predictive value of the traditional antigen-based and the new epitopebased approaches. We showed that the two approaches were correlated, but that the epitope load was more informative, as antigenic mismatches may over- or underestimate the real level of incompatibility.

Before the development of single antigen beads, Dankers et al. found a correlation between graft failure, DSA and the number of "triplet" (three amino acid epitope) mismatches ${ }^{26}$. More recently, using the latest "eplet" version of HLAMatchmaker and single-antigen bead assays, Wiebe et al. showed that class II epitope loads, together with non-adherence and acute rejection, were independent risk factors of long-term dnDSA ${ }^{21}$. 
We confirmed that in the context of immunosuppression minimization, epitope load is useful to identify patients at highest risk of developing dnDSA rapidly after the modification, whatever the class of these DSA. Epitope load was more strongly associated with the development of class I or II dnDSA than the number of antigenic or allelic mismatches, with a discriminative threshold of 27 class I+II epitopic mismatches. Furthermore, the number of mismatched antibody-verified epitopes was more closely associated with dnDSA development than the total number of epitopes. It is likely that many (if not all) of the not verified epitopes, have physicochemical properties or localization that do not make them accessible to alloantibodies.

Another advantage of the epitopic approach is the ability to study the immunogenicity of epitopes. Indeed, our study, as the one by Wiebe et $\mathrm{al}^{21}$, suggests that some mismatched antibody-verified epitopes are more frequently associated with the development of dnDSA than others and, thus, are more immunogenic, which is possibly based on their exposed position. Pre-transplant identification of mismatched or targeted epitopes (for immunized patients) could be a new tool for assessing immunological risk. One could hypothesize that the greater the epitope load, the higher the probability that the recipient's immune system will respond to at least one immunogenic epitope. A limitation of our study is the small cohort size and the lack of power that prevented us to show a significantly higher discriminative value of epitope loads in ROC curve analysis, despite the positive result of logistic regression. Thus, the relative role of epitope load should be explored in larger populations. Moreover, for one third of patients, epitope load was calculated with allelic typing deduced from generic typing using the HaploStats application ${ }^{27}$, because DNA was not available anymore; this may increase the uncertainty of the data. Nevertheless, we confirmed the accuracy of HaploStats for the French Caucasian population ${ }^{28}$ (Table S3). Moreover, DRB3/4/5 and DQA1 typing were rarely performed because of their strong linkage disequilibrium with DRB1 and DQB1 alleles ${ }^{29,30}$. We have shown in Table S4 and S5 that the potential errors would have a weak impact on epitope load calculation. Eventually, we did not study DQA1, DPB1 and DPA1 epitope loads in relation with dnDSA because only two patients developed DQA1 and two others DPB1 dnDSA, and always in association with other DSA. Moreover, these DSA are not consensually recognized as pathogenic as those targeting other HLA loci molecules. 
We did not identify any association between epitope load and TCMR or ABMR. TCMR involves T-cell epitopes that are different from B-cell epitopes, although they may be involved in dnDSA generation ${ }^{31}$ Sapir-Pichhadze et al. described an association between transplant glomerulopathy and the DR+DQ eplet load in kidney transplant recipients ${ }^{32}$. Using an electronic system of adherence monitoring, Wiebe et al. found that the combination of poor adherence and higher epitope load acted synergistically, but not separately, to determine the risk of ABMR (DQ) or graft loss (DR and DQ) ${ }^{33}$. In our study, the adherence was not specifically studied, but the close follow-up during the first posttransplantation year and the context of a clinical trial ${ }^{22}$ make the probability of poor adherence low. Moreover, the similar exposure to everolimus in patients who developed or not DSA, suggests that it did not play a major role in DSA occurrence. Interestingly, we found a lower epitope load threshold for the development of DQ dnDSA than Wiebe et $\mathrm{al}^{21}$ (8 versus 17 ), possibly because we did not take into account DQA epitopes.

In our study, conversion to everolimus may have played a critical role in the development of dnDSA and therefore cannot be advocated, even if patients at risk may be identified. Given that antibody-verified epitope load was higher in the everolimus arm, we cannot rule out that patients under everolimus would have eventually developed dnDSA while remaining on cyclosporine. However, dnDSA appeared more frequently and earlier after conversion to everolimus. Moreover, even if TCMR was observed in $34.5 \%$ of patients who developed dnDSA, most of the patients (19/29) who developed dnDSA did not experience TCMR. This was confirmed in the multivariate analysis that found that epitope load was the only independent factor associated with dnDSA. Our study was similar to the one by Hricik et al. ${ }^{34}$ but we benefited of a larger cohort. They showed retrospectively in 14 kidney transplant recipients randomized to wean off tacrolimus that the 5 patients who developed anti-DQ dnDSA had an epitope load above the threshold of 16 epitopic mismatches ${ }^{34}$.

In conclusion, our study revealed that epitope load is a more informative and predictive tool than the number of antigenic or allelic mismatches for determining the risk of posttransplant allosensitization, particularly the short-term risk following minimization of immunosuppression. We think that in a daily practice, when reduction of immunosuppression is discussed, clinicians could right now implement epitope load for the identification of patients for whom such a minimization may be hazardous. If epitope 
load is above the threshold, minimization should only be performed in case of clinical indication and with a strict follow up of dnDSA. We think that epitope load, and not solely antigenic mismatches, should also be calculated and provided in published clinical studies to compare the level of incompatibility of two groups of patients, particularly in clinical trials assessing a modification of immunosuppression. This study provides a basis for large-scale studies and for the use of epitope load in allocation policies.

\section{Methods}

\section{Patient population}

The patients included in our study had been previously randomized in a controlled trial for conversion from CsA to everolimus three months post-transplantation ${ }^{22}$. In brief, kidney transplant recipients were randomized into two treatment groups corresponding to maintenance on CsA or conversion to everolimus, both in conjunction with mycophenolic acid and steroid treatment. Patients were excluded if they had experienced TCMR prior to randomization, or were positive for DSA. Patients randomized to CsA withdrawal received everolimus adjusted to target a C0 concentration of 6-10 ng/mL. Mycophenolic acid was started at $720 \mathrm{mg}$ b.i.d and decreased at $360 \mathrm{mg}$ b.i.d. after month-3 only in the everolimus arm. The diagnosis of ABMR was made according to the 09' update of the Banff 97 classification ${ }^{35}$.

\section{Determination of HLA allelic typing}

DNA was available for retrospective complete allelic typing (A,B,C,DRB1,DQB1) for 68 recipients and 62 donors in the everolimus arm. This retrospective typing was performed at the laboratory of Immunology of Saint-Louis Hospital, with next generation sequencing (Reagents : GenDX company, analyzed on a Illumina MiSeq sequencer with the NGSEngine software) (Bedia, Chavenay, France) or high resolution PCR-specific sequence oligonucleotides (HD-SSO LabType, One Lambda, Ingen, Chatenay-Malabry, France), the latter when only two loci or less were to be analyzed. For the remaining cases, only the initial typing locally performed by lymphocytotoxicity, sequence-specific PCR primers (SSP) or low-resolution SSO, was available. DQA typing was only available for 27 donors and 14 recipients. For the remaining patients, DQA1 typing was inferred from the well-described tight linkage disequilibrium with DRB1 and 
DQB1 alleles ${ }^{29}$. DRB3/4/5 typing is not performed in France but is also inferred from the well-known associations with DRB1 genes ${ }^{30}$. DPB and DPA typing were not performed. The missing allelles were inferred from their haplotype associations with HaploStats, a modified expectation-maximization algorithm provided by the National Marrow Donor Program ${ }^{27}$. The frequency of haplotypes was questioned for Caucasian populations(including Middle East and Africa's North Coast). HaploStats outputs the list of all possible unphased allelic typings for HLA A, B, C, DRB1, DRB3/4/5, and DQB1 loci and the likelihood for each pair of haplotypes. These typing were confirmed when possible with the list of common French HLA haplotypes ${ }^{28}$, which may lead to some infrequent errors (Table S3).

\section{Determination of epitope load with HLAMatchmaker software}

Once computed, allelic donor and recipient HLA typings were entered into HLAMatchmaker18, a Microsoft Excel-based software (ABCepletmatching Vs1 for class I and DRDQDPepletmatching Vs1 for class II). This algorithm applies two principles: (1) each HLA antigen is represented as a distinct string of structurally defined epitopes that correspond to many potential immunogens that can induce specific antibodies, and (2) patients cannot make antibodies against epitopes expressed by their own HLA molecules. It assesses donor-recipient compatibility through intra-locus and inter-locus comparisons. Class I and II epitope loads are the number of epitopes expressed by the donor but not by the recipient.

\section{Identification of DSA and of targeted epitopes}

To rule out the presence of DSA before transplantation, all centers conducted pretransplant systematic Luminex single antigen (SA) or Luminex screenings (every 3 to 6 months). A Luminex SA test was performed if the screening became positive.

During the post-transplantation period, all patients underwent Luminex screening at month-3 (randomization), month-12 (end of the study) and then annually. A Luminex SA test was performed if the screening became positive. Luminex assays were performed using One Lambda kits (Canoga Park, CA) except for three patients tested using Lifecodes kits (Immucor, Norcross, GA). In DQ7negative patients who received a DQ7positive graft and developed anti-DQ7 dnDSA, we used the HLAMatchmaker DRDQDP software to determine which DQ7 epitopes were 
targeted by serum antibodies. Briefly, we entered the MFI of the class II Luminex single antigen beads into HLAMatchmaker ("DRDQDP antibody analysis V01"). The DQ epitopes of the recipient and of the negative beads were excluded as potential candidates for targeted epitopes. We examined the positive beads and determined which epitopes shared across these positive alleles could explain the reactivity pattern.

\section{Statistical analysis}

The results are expressed as the mean \pm SD for continuous variables or percentages for categorical data. Comparisons were based on Student's t tests for normally distributed continuous data or Wilcoxon Rank Sums tests for nonparametric univariate analysis, and on $\chi^{2}$ tests or exact Fisher's tests for categorical data. Receiver operating characteristic (ROC) curve analysis was performed with the pROC package ${ }^{36}$ to determine the optimal epitopic mismatch threshold that best predicted dnDSA development. This value was associated with the highest true positive rate and the lowest false positive rate. A two-sided p-value of 0.05 was considered statistically significant. AUC corresponding to the different types of mismatches were compared using the Delong method. Crude and adjusted odds ratio of graft loss according to number of epitopic mismatches were estimated using logistic regression. Potential adjustment covariates were antigenic mismatches, mean everolimus level, recipient and donor ages, and TCMR. Only covariates associated with a p-value $<0.1$ were included in the final model using stepwise forward selection. Statistical analyses were performed using R software. R: A language and environment for statistical computing. R Foundation for Statistical Computing, Vienna, Austria.

\section{Disclosures}

None 


\section{Supplementary Materials}

'Supplementary information is available at Kidney International's website'

Supplementary Table 1: HLA matching of the two arms of the randomized trial

Supplementary Table 2 HLA mismatches according to the occurrence of TCMR or $\mathrm{ABMR}$ and the occurrence of dnDSA in patients with rejection

Supplementary Table 3: Comparison of allelic typing assumed with HaploStats application based on generic typing and true allelic typing for frequent French haplotypes.

Supplementary Table 4: Modification of total and antibody-verified DR epitope loads with the different DRB3/4/5 alleles

Supplementary Table 5. Difference in DQA epitope expression in case of error in DQA allele inference

Supplementary Figure 1. Evolution of renal function during the follow-up.

Supplementary Figure 2. Comparison of class I and class II antigenic and antibodyverified epitope mismatches.

Supplementary Figure 3. Distribution of patients with everolimus discontinuation, Tcell mediated rejection and de novo DSA 


\section{References}

1. Morris PJ, Johnson RJ, Fuggle S V, et al. Analysis of factors that affect outcome of primary cadaveric renal transplantation in the UK. HLA Task Force of the Kidney Advisory Group of the United Kingdom Transplant Support Service Authority (UKTSSA). Lancet. 1999; 354: 1147-1152.

2. Opelz G, Wujciak T, Döhler B, et al. HLA compatibility and organ transplant survival. Collaborative Transplant Study. Rev Immunogenet. 1999; 1: 334-342.

3. Opelz G, Döhler B. Effect of human leukocyte antigen compatibility on kidney graft survival: comparative analysis of two decades. 2007;Transplantation 84: 137-143.

4. Williams RC, Opelz G, McGarvey CJ, et al. The Risk of Transplant Failure With HLA Mismatch in First Adult Kidney Allografts From Deceased Donors.

Transplantation. 2016; 100: 1094-1102.

5. Su X, Zenios SA, Chakkera H, et al. Diminishing Significance of HLA Matching in Kidney Transplantation. Am J Transplant. 2004; 4: 1501-1508.

6. Wiebe C, Gibson IW, Blydt-Hansen TD, et al. Evolution and Clinical Pathologic Correlations of De Novo Donor-Specific HLA Antibody Post Kidney Transplant. Am J Transplant. 2012;12: 1157-1167.

7. Wiebe C, Rush DN, Nevins TE, et al. Class II Eplet Mismatch Modulates Tacrolimus Trough Levels Required to Prevent Donor-Specific Antibody Development. J Am Soc Nephrol. 2017;28:3353-336.

8. Willicombe M, Brookes P, Sergeant R, et al. De Novo DQ Donor-Specific Antibodies Are Associated With a Significant Risk of Antibody-Mediated Rejection and Transplant Glomerulopathy. Transplant. 2012;94: 172-177.

9. Hidalgo LG, Campbell PM, Sis B, et al. De Novo Donor-Specific Antibody at the Time of Kidney Transplant Biopsy Associates with Microvascular Pathology and Late Graft Failure. Am J Transplant. 2009; 9: 2532-2541.

10. Everly MJ, Rebellato LM, Haisch CE, et al. Incidence and Impact of De Novo DonorSpecific Alloantibody in Primary Renal Allografts. Transplantation. 2013 95: 410417.

11. Ginevri F, Nocera A, Comoli P, et al. Posttransplant De Novo Donor-Specific HLA Antibodies Identify Pediatric Kidney Recipients at Risk for Late Antibody- 
Mediated Rejection. Am J Transplant. 2012; 12: 3355-3362.

12. DeVos JM, Gaber AO, Knight RJ, et al. Donor-specific HLA-DQ antibodies may contribute to poor graft outcome after renal transplantation. Kidney Int. 2012 82: 598-604.

13. Yamamoto T, Watarai Y, Takeda A, et al. De Novo Anti-HLA DSA Characteristics and Subclinical Antibody-Mediated Kidney Allograft Injury. Transplantation. 2016; 100: 2194-2202.

14. Mao Q, Terasaki PI, Cai J, et al. Extremely high association between appearance of HLA antibodies and failure of kidney grafts in a five-year longitudinal study. Am J Transplant. 2007; 7: 864-871.

15. El-Awar N, Lee J-H, Tarsitani C, Terasaki PI. HLA Class I Epitopes: Recognition of Binding Sites by mAbs or Eluted Alloantibody Confirmed With Single Recombinant Antigens. Hum Immunol. 2007; 68: 170-180.

16. Cai J, Terasaki PI, Mao Q, et al. Development of Nondonor-Specific HLA-DR Antibodies in Allograft Recipients Is Associated with Shared Epitopes with Mismatched Donor DR Antigens. Am J Transplant. 2006; 6: 2947-2954.

17. Duquesnoy RJ: A structurally based approach to determine HLA compatibility at the humoral immune level. Hum Immunol. 2006; 67: 847-862.

18. Duquesnoy RJ: Clinical usefulness of HLAMatchmaker in HLA epitope matching for organ transplantation. Curr Opin Immunol. 2008; 20: 594-601.

19. El-Awar NR, Akaza T, Terasaki PI, Nguyen A: Human leukocyte antigen class I epitopes: update to 103 total epitopes, including the C locus. Transplantation. 2007; 84: 532-540.

20. Duquesnoy RJ, Marrari M, Tambur AR, et al. First report on the antibody verification of HLA-DR, HLA-DQ and HLA-DP epitopes recorded in the HLA Epitope Registry. Hum Immunol. 2014; 75: 1097-1103.

21. Wiebe C, Pochinco D, Blydt-Hansen TD, et al. Class II HLA Epitope Matching-A Strategy to Minimize De Novo Donor-Specific Antibody Development and Improve Outcomes: Class II Epitope Matching to Minimize De Novo DSA. Am J Transplant. 2013; 13: 3114-3122.

22. Rostaing L, Hertig A, Albano L, et al. Fibrosis progression according to epithelialmesenchymal transition profile: A randomized trial of everolimus versus CsA. Am J Transplant. 2015; 15: 1303-1312. 
23. Liefeldt L, Brakemeier S, Glander P, et al. Donor-specific HLA antibodies in a cohort comparing everolimus with cyclosporine after kidney transplantation. Am J Transplant. 2012; 12: 1192-1198.

24. Saper MA, Bjorkman PJ, Wiley DC. Refined structure of the human histocompatibility antigen HLA-A2 at 2.6 A resolution. J Mol Biol. 1991; 219: 277319.

25. Gorga JC, Brown JH, Jardetzky T, et al. Crystallization of HLA-DR antigens. Res Immunol. 1991; 142: 401-407.

26. Dankers MKA, Witvliet MD, Roelen DL, et al. The number of amino acid triplet differences between patient and donor is predictive for the antibody reactivity against mismatched human leukocyte antigens. Transplantation. 2004; 77: 12361239.

27. Gragert L, Madbouly A, Freeman J, Maiers M. Six-locus high resolution HLA haplotype frequencies derived from mixed-resolution DNA typing for the entire US donor registry. Hum Immunol. 2013; 74: 1313-1320.

28. Pedron B, Yakouben K, Adjaoud D, et al. Listing of Common HLA Alleles and Haplotypes Based on the Study of 356 Families Residing in the Paris, France, Area: Implications for Unrelated Hematopoietic Stem Cell Donor Selection. Hum Immunol. 2005; 66: 720-730.

29 Klitz W, Maiers M, Spellman S, et al.New HLA haplotype frequency reference standards: high-resolution and large sample typing of HLA DR-DQ haplotypes in a sample of European Americans. Tissue Antigens. 2003;62:296-307.

30 Knipper AJ, Hakenberg P, Enczmann J, et al.HLA-DRB1,3,4,5 and -DQB1 allele frequencies and HLA-DR/DQ linkage disequilibrium of 231 German caucasoid patients and their corresponding 821 potential unrelated stem cell transplants.Hum Immunol. 2000;61:605-614.

31. Lachmann N, Niemann M, Reinke P, et al.Donor-Recipient Matching Based on Predicted Indirectly Recognizable HLA Epitopes Independently Predicts the Incidence of De Novo Donor-Specific HLA Antibodies Following Renal Transplantation. Am J Transplant. 2017;17:3076-3086.

32. Sapir-Pichhadze R, Tinckam K, Quach K, et al.. HLA-DR and -DQ Eplet Mismatches and Transplant Glomerulopathy: A Nested Case-Control Study: HLA-DR + DQ Eplet Mismatches and TG. Am J Transplant. 2015; 15: 137-148. 
33. Wiebe C, Nevins TE, Robiner WN, et al. The Synergistic Effect of Class II HLA Epitope-Mismatch and Nonadherence on Acute Rejection and Graft Survival. Am J Transplant. 2015; 15: 2197-2202.

34. Hricik DE, Formica RN, Nickerson P, et al. Clinical Trials in Organ Transplantation09 Consortium. Adverse Outcomes of Tacrolimus Withdrawal in ImmuneQuiescent Kidney Transplant Recipients. J Am Soc Nephrol. 2015; 26:3114-3122.

35. Sis B, Mengel M, Haas M, et al. Banff '09 meeting report: antibody mediated graft deterioration and implementation of Banff working groups. Am J Transplant. $2010 ; 10: 464-71$.

36. Robin X, Turck N, Hainard A, Tiberti N, Lisacek F, Sanchez JC and Müller M. "pROC: an open-source package for R and S+ to analyze and compare ROC curves". BMC Bioinformatics. 2011; 12: 77.

\section{Acknowledgments}

The authors would like thank Dr Vincent Elsermans (Lille), Dr Nicolas Congy (Toulouse), Dr Anne Parissiadis (Strasbourg), Dr Alice Aarnink (Nancy), Dr Valérie Dubois (Lyon), Dr Abdelhamid Assaqa (Tours), Dr Nicolas Guillaume (Amiens), Dr Olivier Toutirais (Caen) Dr Dominique Masson (Grenoble), Dr Thierry Tabary (Reims), M. Fabien Duthe for providing the HLA data. 


\section{Figure Legends}

Figure 1. Number of patients with occurrence of de novo DSA in the study population. Patients were included in the trial before transplantation, received a treatment based on cyclosporine and were randomized at three months posttransplantation to be maintained on cyclosporine or switched to everolimus. Abbreviations: MPA mycophenolic acid

\section{Figure 2. Graft and patient post-transplantation survival.}

A) Patient survival according to the development of dnDSA (red line) or not (black line).

B) Death-censored graft survival according to the development of dnDSA (red line) or not (black line). C) Death-censored graft survival according to the treatment arm: cyclosporine (red line) or everolimus (black line). p value corresponds to log-rank test.

\section{Figure 3. Comparison of the numbers of antigenic, allelic and epitopic mismatches} in the study population. A and B) Comparison of class I (A) and class II (B) antigenic and epitope mismatches. For example, patients with a maximal value of 6 class I antigenic mismatches actually displayed an epitope load ranging from 13 to 36 . Conversely, patients with the median value $(n=15)$ of class I epitopic mismatches displayed 2 to 6 antigenic mismatches. The maximal number of antigenic mismatches is 6 for class I ( 2 for each locus HLA-A, B and Cw) and 4 for class II (2 for DR and DQB locus). C and D) Comparison of class II antigenic and allelic mismatches including DQA alleles (C), and of class II allelic and epitopic mismatches including DQA alleles (D). Patients with 3, 4, 5, 6 and, to a lesser degree, 7/8 class II allelic mismatches had very similar distributions of epitope load, although all these patients would be considered as having a growing level of incompatibility. Conversely, patients with a given number of allelic mismatches, for example 6, may have many epitopic mismatches ranging from 10 to 51. E and F) Comparison of class II antigenic and allelic mismatches excluding DQA alleles (E) and class II allelic and epitope mismatches excluding DQA alleles (F). Each floating bar represents the minimum and maximum values, and the line corresponds to the median value. The maximal number of allelic mismatches is 8 (Panels C/D: 2 for each locus HLA-DRB1, DRBW, DQB, DQA) or 6 without DQA (Panels E/F). 
Figure 4. Evaluation of HLA compatibility with antigenic, allelic and epitope mismatches. A) An example of two patients with the same number of class II antigenic $(n=2)$ and allelic $(n=4)$ mismatches but with different epitope loads (11 and 48), including DQA epitopes. The second patient developed de novo class II DSA. B) An example of three DQ7-negative recipients who received a DQ7-positive transplant. The same DQ7 antigenic mismatch was associated with different DQ7 specific epitope loads according to the recipient's DQB typing. Alpha chains are shown in pink, beta chains are in blue, and peptides are in brown. Mismatched epitopes are in yellow (beta chain epitopes are shown in normal font, and alpha chain epitopes are shown in italic font).

Figure 5. Distribution of patients who developed or not $\operatorname{dnDSA}$, according to antigenic and epitopic mismatches. Patients with (black dots) or without (empty dots) class I or II dnDSA, according to the total number of antigenic $(A+B+C+D R+D Q B 1)$ and epitopic $(\mathrm{A}+\mathrm{B}+\mathrm{C}+\mathrm{DR}+\mathrm{DQB} 1)$ mismatches. Horizontal dashed/dotted line corresponds to the threshold of 27 epitopic mismatches and vertical line to the threshold of 6 antigenic mismatches (see Table 5).

\section{Figure 6. Survival without de novo DSA.}

In patients from the cyclosporine arm (red line) or everolimus (black line). p-value corresponds to log-rank test

Figure 7. Comparison of specific DQ7 epitopic mismatches in patients who developed or did not develop DQ7 DSA. DQ7 specific epitope load including all DQ7 epitopes (A) or only antibody-verified epitopes (B) in DQ7-negative patients who received a DQ7-positive transplant and did or did not develop a DQ7 dnDSA after transplantation. C) Frequency of mismatched DQ7 epitopes in DQ7-negative patients who received a DQ7-positive transplant and did or did not develop a DQ7 dnDSA. ${ }^{*} \mathrm{p}<0.05$. RR: relative risk of DQ7 dnDSA in cases of mismatched epitopes. 
Table 1: Characteristics of the study population

\begin{tabular}{|c|c|c|c|c|}
\hline Recipients & $\begin{array}{l}\text { Whole } \\
\text { group }\end{array}$ & dnDSA & no dnDSA & p \\
\hline $\mathbf{N}$ & 89 & 29 & 60 & \\
\hline Age, yrs (mean \pm SD) & $48.2 \pm 12.5$ & $42.9 \pm 14.0$ & $50.8 \pm 10.9$ & 0.005 \\
\hline Sex, $N(\%)$ of males & $59(66.3)$ & $22(75.9)$ & $37(61.7)$ & 0.18 \\
\hline Nephropathy, N (\%) & & & & 0.80 \\
\hline Diabetes & $9(10.1)$ & $4(13.8)$ & $5(8.3)$ & \\
\hline Glomerular disease & $28(31.5)$ & $9(31.0)$ & $19(31.7)$ & \\
\hline Nephroangiosclerosis & $5(5.6)$ & $2(6.9)$ & $3(5.0)$ & \\
\hline Interstitial nephritis & $12(13.5)$ & $5(17.2)$ & $7(11.7)$ & \\
\hline Polycystic disease & $16(18.0)$ & $4(13.8)$ & $12(20.0)$ & \\
\hline Other & $11(12.4)$ & $4(13.8)$ & $7(11.7)$ & \\
\hline Unknown & $8(9.0)$ & $1(3.4)$ & $7(11.7)$ & \\
\hline $\begin{array}{l}\text { No dialysis before transplantation, } \\
\mathbf{N}(\%)\end{array}$ & $6(6.7)$ & $1(3.4)$ & $5(8,3)$ & 0.66 \\
\hline Positive PRA, $\mathbf{N}^{\mathrm{a}}(\%)$ & $5(6.5)$ & $0(0)$ & $5(10)$ & 0.16 \\
\hline $\begin{array}{l}\text { Mean PRA (\%) } \\
\text { Donors }\end{array}$ & $0.8 \pm 3.8$ & 0 & $1.2 \pm 4.7$ & 0.09 \\
\hline Age, yrs (mean \pm SD) & $47.5 \pm 14.9$ & $43.4 \pm 14.8$ & $49.4 \pm 14.6$ & 0.07 \\
\hline Deceased donor / living donor (\%) & $92.1 / 7.9$ & $93.1 / 6.9$ & $91.7 / 8.3$ & 1.0 \\
\hline Cerebrovascular death, $\mathbf{N}^{\mathbf{b}}(\%)$ & $46(56.8)$ & $13(50.0)$ & $33(60.0)$ & 0.47 \\
\hline Delayed graft function, $\mathbf{N}(\%)$ & $16(18.0)$ & $7(24.1)$ & $9(15.0)$ & 0.38 \\
\hline T-cell Mediated Rejection, N(\%) & $20(22.5)$ & $10(34.5)$ & $10(16.7)$ & 0.10 \\
\hline
\end{tabular}

a: information available for 77 patients

b: information available for 81 patients

Abbreviations. dnDSA: de novo donor-specific antibody; SD: standard deviation;

PRA: panel reactive antibody 
Table 2: Antigenic, allelic and epitopic mismatches

\begin{tabular}{|c|c|c|c|c|c|}
\hline & Min & Max & Median & IQR & Mean \pm SD \\
\hline \multicolumn{6}{|l|}{ Class I } \\
\hline Antigenic MM & 1 & 6 & 4 & $3-5$ & $3.8 \pm 1.4$ \\
\hline Allelic MM & 1 & 6 & 4 & $3-5$ & $4.1 \pm 1.3$ \\
\hline All Epitopic MM & 2 & 36 & 15 & $10-19$ & $15.2 \pm 6.4$ \\
\hline Abv Epitopic MM & 1 & 19 & 8 & $5-11$ & $8.5 \pm 4.0$ \\
\hline \multicolumn{6}{|l|}{ Class II } \\
\hline Antigenic MM (DR+DQ) & 0 & 4 & 2 & $1-2$ & $2.0 \pm 1.1$ \\
\hline Allelic MM (w/o DQA) & 1 & 6 & 3 & $3-4$ & $3.3 \pm 1.4$ \\
\hline Allelic MM (with DQA) & 1 & 8 & 4 & $3-5$ & $4.5 \pm 1.8$ \\
\hline All Epitopic MM (w/o DQA) & 0 & 50 & 20 & $11-31$ & $20.9 \pm 12.5$ \\
\hline Abv Epitopic MM & 0 & 26 & 8 & $4-12$ & $8.5 \pm 6.3$ \\
\hline All Epitopic MM (with DQA) & 0 & 65 & 24 & $15-38$ & $26.3 \pm 15.8$ \\
\hline Abv Epitopic MM & 0 & 26 & 9 & $4-14$ & $9.4 \pm 6.8$ \\
\hline \multicolumn{6}{|l|}{ Class I + II } \\
\hline Antigenic MM & 1 & 10 & 6 & $4-7$ & $5.7 \pm 1.9$ \\
\hline Allelic MM & 2 & 12 & 7 & $6-9$ & $7.4 \pm 2.1$ \\
\hline All Epitopic MM (w/o DQA) & 2 & 66 & 36 & $25-49$ & $36.1 \pm 14.6$ \\
\hline Abv Epitopic MM & 1 & 33 & 16 & $12-22$ & $17.0 \pm 7.5$ \\
\hline
\end{tabular}


Table 3: Exposure to imunosuppressive drugs and de novo DSA

\begin{tabular}{|c|c|c|c|}
\hline & De novo DSA & No de novo DSA & $\mathbf{p}$ \\
\hline $\mathrm{T}^{\circ}$ cyclosporine* at randomization & $169.0 \pm 54.0(\mathrm{~N}=14)$ & $166.0 \pm 33.5(\mathrm{~N}=34)$ & 0.93 \\
\hline T2 cyclosporine* at randomization & $851.2 \pm 290.8(\mathrm{~N}=7)$ & $925.7 \pm 381.8(\mathrm{~N}=21)$ & 0.84 \\
\hline $\mathrm{T}^{\circ}$ everolimus $\mathrm{M} 6$, mean $\pm \mathrm{SD}$ & $5.7 \pm 1.8$ & $6.9 \pm 2.9$ & 0.08 \\
\hline $\mathrm{T}^{\circ}$ everolimus M9, mean \pm SD & $7.0 \pm 2.1$ & $7.2 \pm 2.8$ & 0.78 \\
\hline $\mathrm{T}^{\circ}$ everolimus $\mathrm{M} 12$, mean \pm SD & $7.1 \pm 2.1$ & $8.3 \pm 4.5$ & 0.62 \\
\hline Average $\mathrm{T}^{\circ}$ everolimus, mean $\pm \mathrm{SD}$ & $6.4 \pm 1.8$ & $7.4 \pm 2.6$ & 0.08 \\
\hline $\begin{array}{l}\mathrm{T}^{\circ} \text { everolimus } \mathrm{M} 6<6 \mathrm{ng} / \mathrm{mL} \text {, } \% \text { of } \\
\text { patients }\end{array}$ & $52.2 \%$ & $37.3 \%$ & 0.23 \\
\hline $\begin{array}{l}\mathrm{T}^{\circ} \text { everolimus } \mathrm{M} 9<6 \mathrm{ng} / \mathrm{mL}, \% \text { of } \\
\text { patients }\end{array}$ & $31.3 \%$ & $31.0 \%$ & 1.0 \\
\hline $\begin{array}{l}\mathrm{T}^{\circ} \text { everolimus } \mathrm{M} 12<6 \mathrm{ng} / \mathrm{mL}, \% \text { of } \\
\text { patients }\end{array}$ & $34.8 \%$ & $30.2 \%$ & 0.69 \\
\hline Dose Mycophenolate M3 (mg/day) & $1386 \pm 356$ & $1316 \pm 388$ & 0.40 \\
\hline Patients below 1440 mg M3, n(\%) & $8(13.3)$ & $5(17.2)$ & 0.75 \\
\hline Dose Mycophenolate M12 (mg/day) & $711 \pm 328$ & $734 \pm 238$ & 0.75 \\
\hline Patients below 720 mg M12, n(\%) & $12(20.3)$ & $3(11.5)$ & 0.54 \\
\hline
\end{tabular}

*Some patients in the study were monitored with cyclosporine trough level $\left(\mathrm{T}^{\circ}\right)$ or with cyclosporine level two hours after drug intake (T2). N: number of patients corresponding to the presence of DSA and to the type of monitoring. M6/M9/M12 correspond to the protocol visit (at 6, 9 or 12 months after transplantation) at which the level was measured. 
Table 4: Relationship between the occurrence of de novo DSA and antigenic, allelic and epitopic mismatches

\begin{tabular}{|c|c|c|c|c|c|c|c|c|}
\hline \multirow{3}{*}{$\begin{array}{c}\mathbf{N} . \\
\text { patients } \\
\text { (DSA+ / } \\
\text { DSA-) } \\
\end{array}$} & \multicolumn{2}{|c|}{$\begin{array}{c}\text { N. of Antigenic } \\
\text { mismatches }\end{array}$} & \multicolumn{2}{|c|}{$\begin{array}{l}\text { N. of Allelic } \\
\text { mismatches }\end{array}$} & \multicolumn{2}{|c|}{$\begin{array}{l}\text { N. of Epitope } \\
\text { mismatches }\end{array}$} & \multicolumn{2}{|c|}{$\begin{array}{c}\text { N. of abv Epitope } \\
\text { mismatches }\end{array}$} \\
\hline & (DSA+ vs & & (DSA+ & & (DSA+ vs & & (DSA+vs & \\
\hline & DSA-) & $\mathrm{p}$ & vs DSA-) & $p$ & DSA-) & $\mathrm{p}$ & DSA-) & $\mathrm{p}$ \\
\hline \multicolumn{9}{|c|}{ Class I or II DSA } \\
\hline & $6.5 \pm 1.8$ vs & & $8.2 \pm 2.1$ vs & & $44.5 \pm 11.6$ vs & & $21.6 \pm 6.3$ vs & \\
\hline $29 / 60$ & $5.4 \pm 1.8$ & 0.015 & $7.1 \pm 2.1$ & 0.026 & $32.0 \pm 14.2$ & $<0.0005$ & $14.8 \pm 7.0$ & 5.7 e-5 \\
\hline \multicolumn{9}{|c|}{ Class I DSA } \\
\hline & $4.8 \pm 0.8$ vs & & $5.0 \pm 0.7$ vs & & $23.2 \pm 7.0$ vs & & $13.2 \pm 3.1$ vs & \\
\hline $5 / 84$ & $3.7 \pm 1.4$ & 0.07 & $4.1 \pm 1.3$ & 0.11 & $14.7 \pm 6.1$ & 0.014 & $8.2 \pm 3.9$ & 0.009 \\
\hline \multicolumn{9}{|c|}{ Class II DSA * } \\
\hline & $2.5 \pm 0.9$ vs & & $3.8 \pm 1.4$ vs & & $27.6 \pm 9.9$ vs & & $12.1 \pm 5.4$ vs & \\
\hline $28 / 61$ & $1.7 \pm 1.2$ & 0.003 & $3.0 \pm 1.3$ & 0.024 & $17.9 \pm 12.4$ & 0.0003 & $6.8 \pm 6.1$ & 4.8 e-5 \\
\hline \multicolumn{9}{|l|}{ DR DSA } \\
\hline & $1.2 \pm 0.4$ vs & & $1.2 \pm 0.4 \mathrm{vs}$ & & $16.8 \pm 8.2$ vs & & $7.0 \pm 4.5$ vs & \\
\hline $6 / 83$ & $1.0 \pm 0.6$ & 0.45 & $1.3 \pm 0.6$ & 0.41 & $10.4 \pm 7.8$ & 0.07 & $3.5 \pm 3.5$ & 0.04 \\
\hline \multicolumn{9}{|l|}{ DQ DSA * } \\
\hline & $1.3 \pm 0.5$ vs & & $1.4 \pm 0.5$ vs & & $13.5 \pm 5.2$ vs & & $6.8 \pm 3.3$ vs & \\
\hline 25 / 64 & $0.9 \pm 0.7$ & 0.006 & $1.2 \pm 0.6$ & 0.18 & $8.7 \pm 8.2$ & 0.0005 & $3.9 \pm 4.8$ & $<0.0005$ \\
\hline
\end{tabular}

Abbreviations: N number, abv: antibody-verified, * DQ and Class II mismatches do not include DQA 
Table 5. Thresholds of antigenic, allelic and epitope mismatches predictive of the occurrence of dnDSA

\begin{tabular}{|c|c|c|c|c|}
\hline & Antigenic MM & Allelic MM & Epitopic MM & Abv Epitopic MM \\
\hline \multicolumn{5}{|l|}{ DSA I or II } \\
\hline AUC & 0.658 & 0.645 & 0.749 & 0.764 \\
\hline $\mathrm{P}^{\mathrm{a}}$ (comparison with antigenic MM) & -- & 0.71 & 0.10 & 0.06 \\
\hline Threshold & 6 & 7 & 27 & 15 \\
\hline $\mathrm{N}$ patients(\%) above the threshold & $50(56.2 \%)$ & $60(67.4)$ & $62(69.7)$ & $56(62.9)$ \\
\hline Freq of DSA (above vs below, $\%$ ), $\mathrm{p}^{\mathrm{b}}$ & $\begin{array}{l}42.0 \text { vs } 20.5 \\
p=0.03\end{array}$ & $\begin{array}{l}41.7 \text { vs } 13.8 \\
p=0.009\end{array}$ & $\begin{array}{l}45.2 \text { vs } 3.7 \\
p=0.0001\end{array}$ & $\begin{array}{l}48.2 \text { vs } 6.1 \\
p=4.2 \text { e- } 5\end{array}$ \\
\hline $\mathrm{RR} 95 \mathrm{Cl}$ & $2.05[1.02-4.12]$ & $3.02[1.2-7.9]$ & $12.2[1.7-85.1]$ & $8.0[2.0-31.3]$ \\
\hline \multicolumn{5}{|l|}{ DSA CLASS I } \\
\hline AUC & 0.738 & 0.710 & 0.830 & 0.849 \\
\hline $\mathrm{p}^{\mathrm{a}}$ (comparison with antigenic MM) & -- & 0.59 & 0.36 & 0.16 \\
\hline Threshold & 4 & 5 & 19 & 10 \\
\hline $\mathrm{N}$ patients(\%) above the threshold & $55(61.8)$ & $37(41.6)$ & $26(29.2)$ & $35(39.3)$ \\
\hline Freq of DSA (above vs below, $\%$ ), $\mathrm{p}^{\mathrm{b}}$ & $\begin{array}{l}9.1 \text { vs } 0.0 \\
p=0.07\end{array}$ & $\begin{array}{l}10.8 \text { vs } 1.9 \\
p=0.16\end{array}$ & $\begin{array}{l}15.4 \text { vs } 1.6 \\
p=0.025\end{array}$ & $\begin{array}{l}14.3 \text { vs } 0.0 \\
p=0.008\end{array}$ \\
\hline $\mathrm{RR} 95 \mathrm{Cl}$ & NA & $5.6[0.7-48.3]$ & $9.7[1.1-82.6]$ & NA \\
\hline \multicolumn{5}{|l|}{ Class II DSA ${ }^{\mathrm{c}}$} \\
\hline AUC & 0.684 & 0.644 & 0.738 & 0.769 \\
\hline $\mathrm{p}^{\mathrm{a}}$ (comparison with antigenic $\mathrm{MM}$ ) & -- & 0.40 & 0.34 & 0.15 \\
\hline Threshold & 2 & 3 & 18 & 10 \\
\hline $\mathrm{N}$ patients(\%) above the threshold & $64(71.9)$ & $67(75.3)$ & $50(56.2)$ & $61(68.5)$ \\
\hline Freq of DSA (above vs below, $\%$ ), $\mathrm{p}^{\mathrm{b}}$ & $\begin{array}{l}39.1 \text { vs } 0.0 \\
p=0.002\end{array}$ & $\begin{array}{l}32.8 \text { vs } 13.6 \\
p=0.08\end{array}$ & $\begin{array}{l}44.0 \text { vs } 7.7 \\
p=1.10-4\end{array}$ & $\begin{array}{l}39.3 \text { vs } 3.6 \\
p<5.10-4\end{array}$ \\
\hline $\mathrm{RR} 95 \mathrm{Cl}$ & NA & $2.4[0.8-7.3]$ & $5.7[1.8-17.7]$ & $11.0[1.6-77.4]$ \\
\hline \multicolumn{5}{|l|}{$\mathrm{DQ}^{\mathrm{DSA}} \mathrm{c}^{\mathrm{c}}$} \\
\hline AUC & 0.667 & 0.577 & 0.737 & 0.741 \\
\hline $\mathrm{p}^{\mathrm{a}}$ (comparison with antigenic $\mathrm{MM}$ ) & -- & 0.02 & 0.23 & 0.22 \\
\hline Threshold & 1 & 2 & 8 & 2 \\
\hline $\mathrm{N}$ patients(\%) above the threshold & $69(77.5)$ & $26(29.2)$ & $56(62.9)$ & $57(64.0)$ \\
\hline Freq of DSA (above vs below, $\%$ ), $\mathrm{p}^{\mathrm{b}}$ & $\begin{array}{l}34.8 \text { vs } 0.0 \\
p=0.002\end{array}$ & $\begin{array}{l}34.6 \text { vs } 23.8 \\
p=0.30\end{array}$ & $\begin{array}{l}41.1 \text { vs } 3.0 \\
p<1.10-4\end{array}$ & $\begin{array}{l}40.4 \text { vs } 3.1 \\
p=1.10-4\end{array}$ \\
\hline $\mathrm{RR} 95 \mathrm{Cl}$ & NA & $1.5[0.7-2.9]$ & $13.6[1.9-95.8]$ & $12.9[1.8-91.2]$ \\
\hline
\end{tabular}

\footnotetext{
Abbreviations. MM: mismatch, AUC: Area Under the Curve, exc: excluding, N: Number, RR: Relative Risk, CI: Confidence Interval, NA: not applicable, Freq: Frequency, a: the first pvalue corresponds to the comparison with the AUC of antigenic mismatches with the De Long methods. The second $p$ value corresponds to the Fisher test performed to compare the proportion of patients with dnDSA in patients with a number of mismatches above the threshold and in patients with a number of mismatches below the threshold, c: DQ and Class II mismatches do not include DQA
} 
Table 6. Factors associated with the development of dnDSA in univariate and multivariate analysis

\begin{tabular}{|c|c|c|c|c|c|c|}
\hline & \multicolumn{3}{|c|}{ Univariate Analysis } & \multicolumn{3}{|c|}{ Multivariate Analysis } \\
\hline & OR & $95 \% \mathrm{Cl}$ & $\mathbf{p}$ & OR & $95 \% \mathrm{Cl}$ & $\mathbf{p}$ \\
\hline Epitope load (per $1 \mathrm{MM}$ increment) & 1.07 & [1.03-1.12] & 0.0004 & 1.05 & [1.01-1.11] & 0.029 \\
\hline Antigenic MM (per $1 \mathrm{MM}$ increment) & 1.41 & [1.09-1.88] & 0.011 & 1.09 & {$[0.76-1.57]$} & 0.62 \\
\hline Mean everolimus level (per $1 \mathrm{ng} / \mathrm{mL}$ ) & 0.82 & {$[0.65-1.01]$} & 0.08 & 0.92 & [0.69-1.18] & 0.52 \\
\hline Recipient Age (per 1 year increment) & 0.95 & {$[0.91-0.98]$} & 0.007 & 0.95 & [0.89-1.01] & 0.11 \\
\hline Donor Age (per 1 year increment) & 0.97 & {$[0.94-1.0]$} & 0.08 & 1.00 & {$[0.95-1.06]$} & 0.95 \\
\hline TCMR (Yes versus No) & 2.63 & [0.94-7.43] & 0.064 & 1.56 & {$[0.48-5.36]$} & 0.48 \\
\hline
\end{tabular}

Abbreviations. MM: mismatch, TCMR: T-cell mediated rejection 
Table 7. Patients with a DQ7 mismatch

\begin{tabular}{|c|c|c|c|c|c|c|c|c|c|c|c|}
\hline \multirow{2}{*}{$\begin{array}{l}\# \\
1 \\
1\end{array}$} & \multirow{2}{*}{$\begin{array}{l}\text { DSA } \\
\text { DQ7 } \\
\text { P }\end{array}$} & \multicolumn{2}{|c|}{$\begin{array}{l}\text { Recipient DQB1 } \\
\text { Allelic typing }\end{array}$} & \multicolumn{2}{|c|}{$\begin{array}{l}\text { Donor DQB1 } \\
\text { Allelic typing }\end{array}$} & \multirow{2}{*}{$\begin{array}{l}\mathrm{AL} \\
\mathrm{MM} \\
1\end{array}$} & \multirow{2}{*}{$\begin{array}{l}\text { DQ7 } \\
\text { Epitope } \\
\text { Load }\end{array}$} & \multirow{2}{*}{$\begin{array}{l}\text { Mismatched } \\
\text { DQ7 epitopes } \\
\text { (Abv) }\end{array}$} & \multirow{2}{*}{ 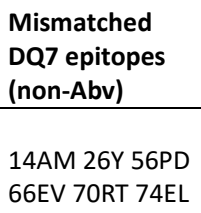 } & \multirow{2}{*}{$\begin{array}{l}\text { Targeted } \\
\text { epitope }\end{array}$} & \multirow{2}{*}{$\begin{array}{l}\text { DQ antigens sharing this } \\
\text { epitope } \\
\text { DQ6,DQ7,DQ8,DQ9 }\end{array}$} \\
\hline & & $* 04: 02$ & $* 02: 02$ & *03:01 & $* 02: 02$ & & & & & & \\
\hline 15 & $P$ & $* 02: 02$ & $* 05: 01$ & *03:01 & $* 05: 01$ & 1 & 12 & $\begin{array}{l}\text { 45EV 52PL 55PP } \\
77 T \text { 140T } 182 \mathrm{~N}\end{array}$ & $\begin{array}{l}\text { 14AM 26Y } \\
\text { 37YA 56PD } \\
\text { 70RT 74EL }\end{array}$ & $55 \mathrm{PP}$ & DQ7,DQ8,DQ9 \\
\hline 25 & $P$ & *06:09 & $* 02: 01$ & *03:01 & $* 02: 01$ & 1 & 8 & $\begin{array}{l}\text { 45EV 52PL 55PP } \\
140 \mathrm{~T} 182 \mathrm{~N}\end{array}$ & 14AM 26Y 56PD & $52 \mathrm{PL} 3$ & DQ4,DQ7,DQ8,DQ9 \\
\hline 27 & $\mathrm{P}$ & $* 05: 03$ & $* 02: 01$ & *03:01 & $* 02: 01$ & 1 & 11 & $\begin{array}{l}45 \mathrm{EV} 52 \mathrm{PL} \\
55 \mathrm{PP} 77 \mathrm{~T} \\
140 \mathrm{~T} 182 \mathrm{~N}\end{array}$ & $\begin{array}{l}\text { 14AM 26Y } \\
\text { 37YA 70RT } \\
\text { 74EL }\end{array}$ & $77 \mathrm{~T}$ & DQ4,DQ6,DQ7,DQ8,DQ9 \\
\hline 41 & $\mathrm{P}$ & $* 05: 01$ & $* 04: 02$ & *03:01 & *06:04 & 2 & 7 & 45EV 55PP & $\begin{array}{l}\text { 14AM 26Y } \\
\text { 56PD 70RT } \\
74 \mathrm{EL}\end{array}$ & $45 \mathrm{EV}$ & DQ7 \\
\hline 45 & $\mathrm{P}$ & *02:02 & $* 05: 01$ & *03:01 & $* 05: 01$ & 1 & 12 & $\begin{array}{l}45 \mathrm{EV} 52 \mathrm{PL} \\
55 \mathrm{PP} 77 \mathrm{~T} \\
140 \mathrm{~T} 182 \mathrm{~N}\end{array}$ & $\begin{array}{l}\text { 14AM 26Y } \\
\text { 37YA 56PD } \\
\text { 70RT 74EL }\end{array}$ & $55 \mathrm{PP}$ & DQ7,DQ8,DQ9 \\
\hline 65 & $\mathrm{P}$ & $* 02: 02$ & $* 02: 02$ & *03:01 & $* 02: 02$ & 1 & 16 & $\begin{array}{l}\text { 45EV 46VY } \\
\text { 28T 52PL 55PP } \\
52 \mathrm{P} 77 \mathrm{~T} 140 \mathrm{~T} \\
182 \mathrm{~N}\end{array}$ & $\begin{array}{l}\text { 14AM 26Y } \\
\text { 37YA 56PD } \\
\text { 70RT 74EL } \\
\text { 135D }\end{array}$ & $\begin{array}{l}\text { DQ } \alpha \beta \\
\text { epitope? }\end{array}$ & $\begin{array}{l}\text { DQB1*03:01- } \\
\text { DQA1*05:03/05:05/06:01 }\end{array}$ \\
\hline 73 & $\mathrm{P}$ & *06:03 & *03:02 & *03:01 & *03:01 & 1 & 3 & $45 \mathrm{EV}$ & 14AM 26Y & $45 \mathrm{EV}$ & DQ7 \\
\hline 107 & $\mathrm{P}$ & $* 05: 02$ & $* 02: 02$ & *03:01 & *02:01 & 1 & 12 & $\begin{array}{l}45 \mathrm{EV} 52 \mathrm{PL} \\
55 \mathrm{PP} 77 \mathrm{~T} \\
140 \mathrm{~T} 182 \mathrm{~N}\end{array}$ & $\begin{array}{l}\text { 14AM 26Y } \\
\text { 37YA 56PD } \\
\text { 70RT 74EL }\end{array}$ & NA & - \\
\hline 173 & $\mathrm{P}$ & $* 05: 02$ & $* 05: 01$ & *03:01 & $* 05: 01$ & 1 & 16 & $\begin{array}{l}\text { 45EV 52PL } \\
55 \mathrm{PP} 77 \mathrm{~T} \\
\text { 84QL 125A } \\
53 \mathrm{~L} 140 \mathrm{~T} \\
182 \mathrm{~N}\end{array}$ & $\begin{array}{l}\text { 14AM 26Y } \\
\text { 37YA 56PD } \\
70 \mathrm{RT} 74 \mathrm{EL} \\
116 \mathrm{~V}\end{array}$ & $55 \mathrm{PP}$ & DQ7,DQ8,DQ9 \\
\hline 187 & $\mathrm{P}$ & *06:02 & $* 02: 02$ & *03:01 & *02:02 & 1 & 8 & $\begin{array}{l}45 \mathrm{EV} 52 \mathrm{PL} \\
55 \mathrm{PP} 140 \mathrm{~T} \\
182 \mathrm{~N}\end{array}$ & $\begin{array}{l}\text { 14AM } 26 \mathrm{Y} \\
70 \mathrm{RT}\end{array}$ & $55 \mathrm{PP}$ & DQ7,DQ8,DQ9 \\
\hline 43 & $\mathrm{~N}$ & $* 06: 02$ & *03:02 & *03:01 & $* 02: 02$ & 2 & 3 & $45 \mathrm{EV}$ & 14AM 26Y & & \\
\hline 49 & $\mathrm{~N}$ & *03:03 & *06:01 & *03:01 & *06:02 & 1 & 1 & $45 \mathrm{EV}$ & & & \\
\hline 63 & $\mathrm{~N}$ & *03:03 & $* 05: 02$ & *03:01 & $* 06: 03$ & 1 & 3 & $45 \mathrm{EV}$ & 14AM $26 \mathrm{Y}$ & & \\
\hline 71 & $\mathrm{~N}$ & *03:02 & *03:02 & *03:01 & *03:01 & 1 & 5 & $45 \mathrm{EV}$ & $\begin{array}{l}\text { 14AM 26Y } \\
56 P D 185 \mathrm{~T}\end{array}$ & & \\
\hline 83 & $\mathrm{~N}$ & *02:02 & $* 02: 01$ & *03:01 & *02:01 & 1 & 16 & $\begin{array}{l}\text { 45EV 46VY } \\
\text { 28T 52PL 55PP } \\
52 \mathrm{P} 77 \mathrm{~T} 140 \mathrm{~T} \\
182 \mathrm{~N}\end{array}$ & $\begin{array}{l}\text { 14AM 26Y } \\
37 \mathrm{YA} 56 \mathrm{PD} \\
66 \mathrm{EV} 70 \mathrm{RT} \\
74 \mathrm{EL}\end{array}$ & & \\
\hline 101 & $\mathrm{~N}$ & *06:04 & $* 02: 01$ & *03:01 & $* 05: 03$ & 2 & 8 & $\begin{array}{l}45 \mathrm{EV} 52 \mathrm{PL} \\
55 \mathrm{PP} 140 \mathrm{~T} \\
182 \mathrm{~N}\end{array}$ & $\begin{array}{l}\text { 14AM 26Y } \\
56 P D\end{array}$ & & \\
\hline 127 & $\mathrm{~N}$ & *05:01 & *03:02 & *03:01 & *02:01 & 2 & 4 & $45 \mathrm{EV}$ & $\begin{array}{l}\text { 14AM 26Y } \\
\text { 56PD }\end{array}$ & & \\
\hline
\end{tabular}




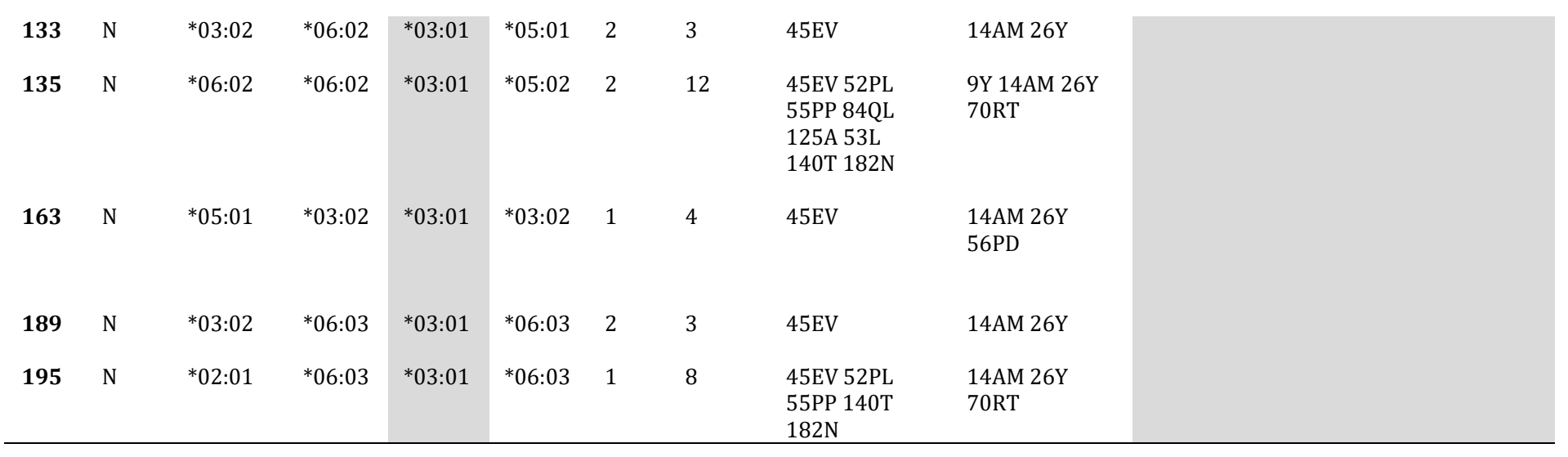

Abbreviations P: positive, N: negative, AL MM: number of DQB1 allelic mismatches, Abv: antibodyverified epitope. * 74EL was the sole non-exposed epitope. 


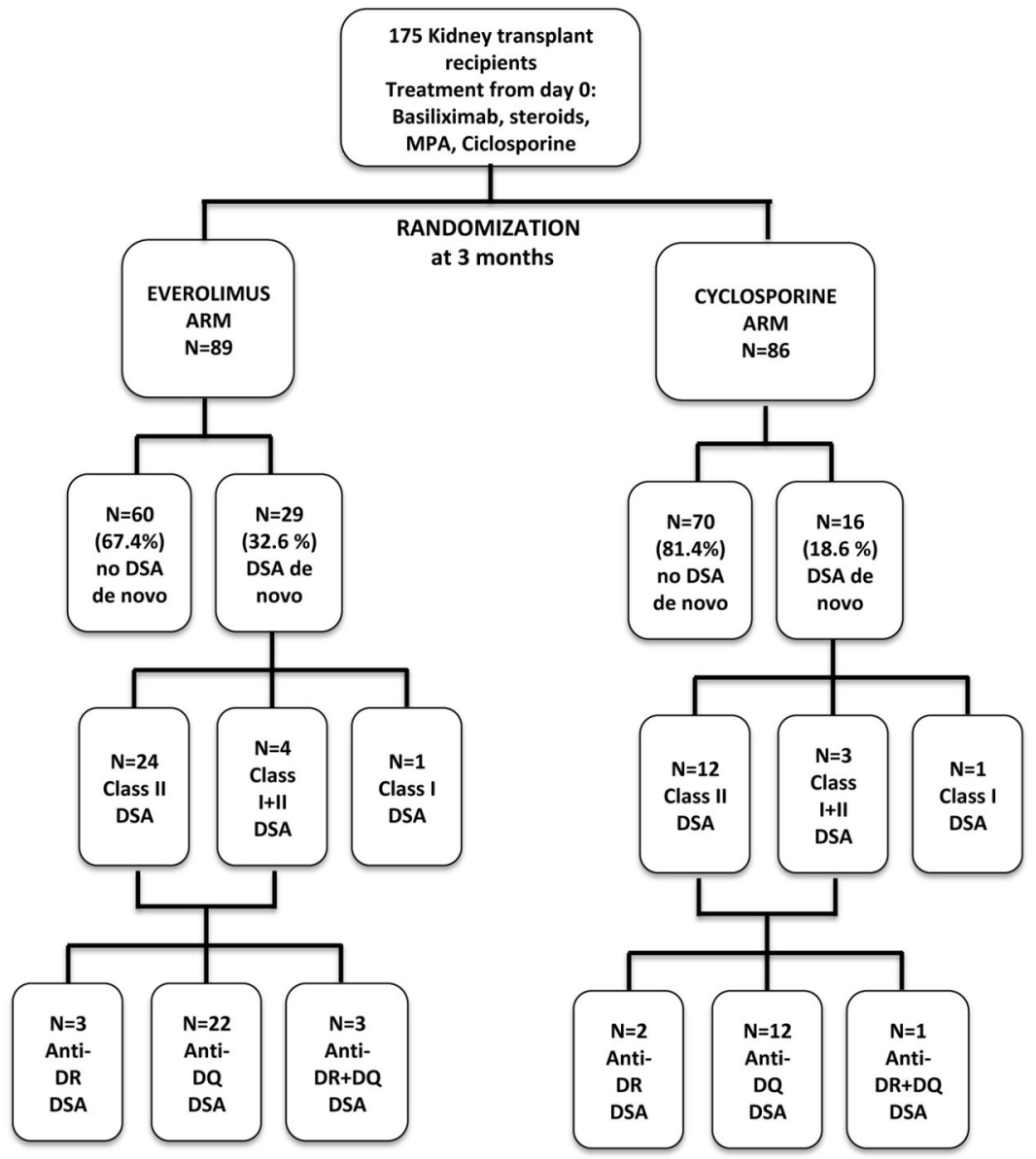




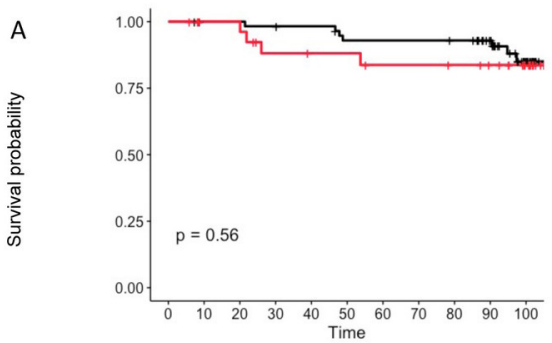

Number at risk

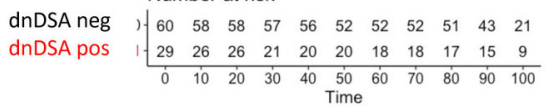

B

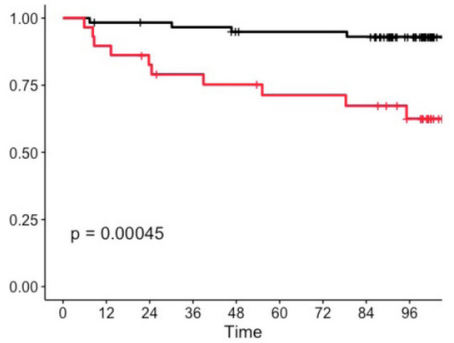

Number at risk

\begin{tabular}{|c|c|c|c|c|c|c|c|c|c|}
\hline dnDSA neg & 0.60 & 58 & 57 & 56 & 53 & 52 & 52 & 51 & 31 \\
\hline dnDSA pos & 29 & 26 & 23 & 21 & 20 & 18 & 18 & 17 & 12 \\
\hline & 0 & 12 & 24 & 36 & $\begin{array}{l}48 \\
\text { Tim }\end{array}$ & 60 & 72 & 84 & 96 \\
\hline
\end{tabular}

C

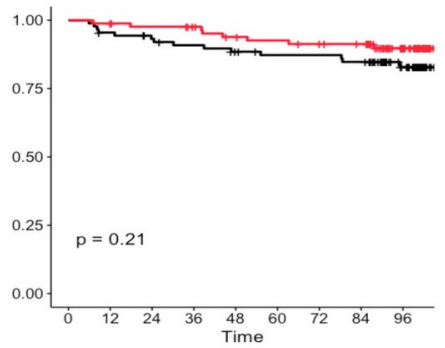

Number at risk

everolimus
cyclosporine $\quad$\begin{tabular}{ccccccccc}
89 & 84 & 80 & 77 & 73 & 70 & 70 & 68 & 43 \\
86 & 85 & 82 & 79 & 74 & 72 & 69 & 67 & 41 \\
\hline 0 & 12 & 24 & 36 & 48 & 60 & 72 & 84 & 96 \\
& & \multicolumn{7}{c}{ Time }
\end{tabular}


Class I Mismatches

A

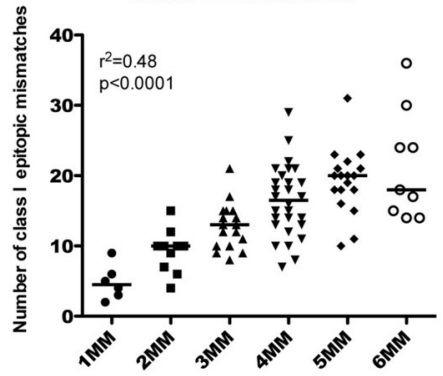

Number of class I antigenic mismatches

Class II antigenic and allelic mismatches

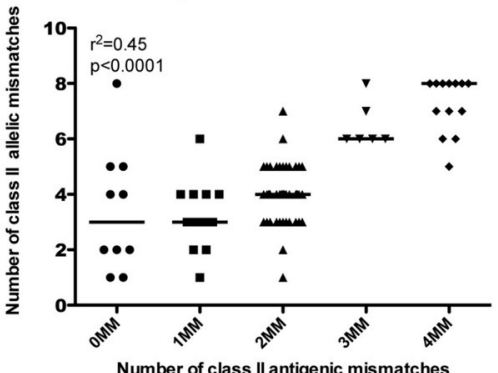

Number of class II antigenic mismatches

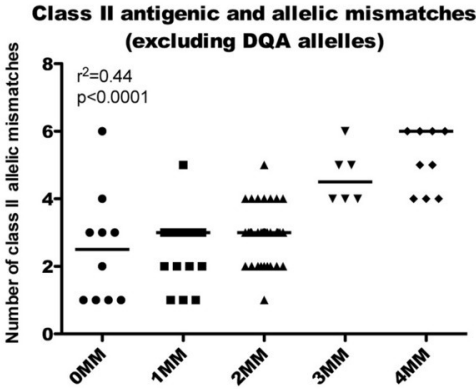

Number of class II antigenic mismatches

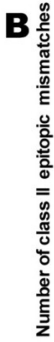

D

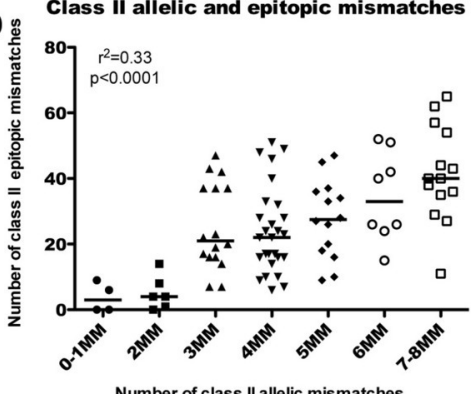

Number of class II allelic mismatches

$\mathbf{F}$

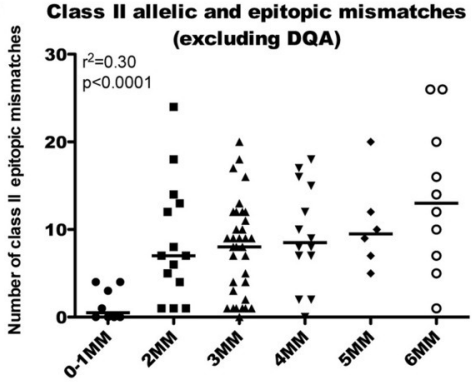

Number of class II allelic mismatches 


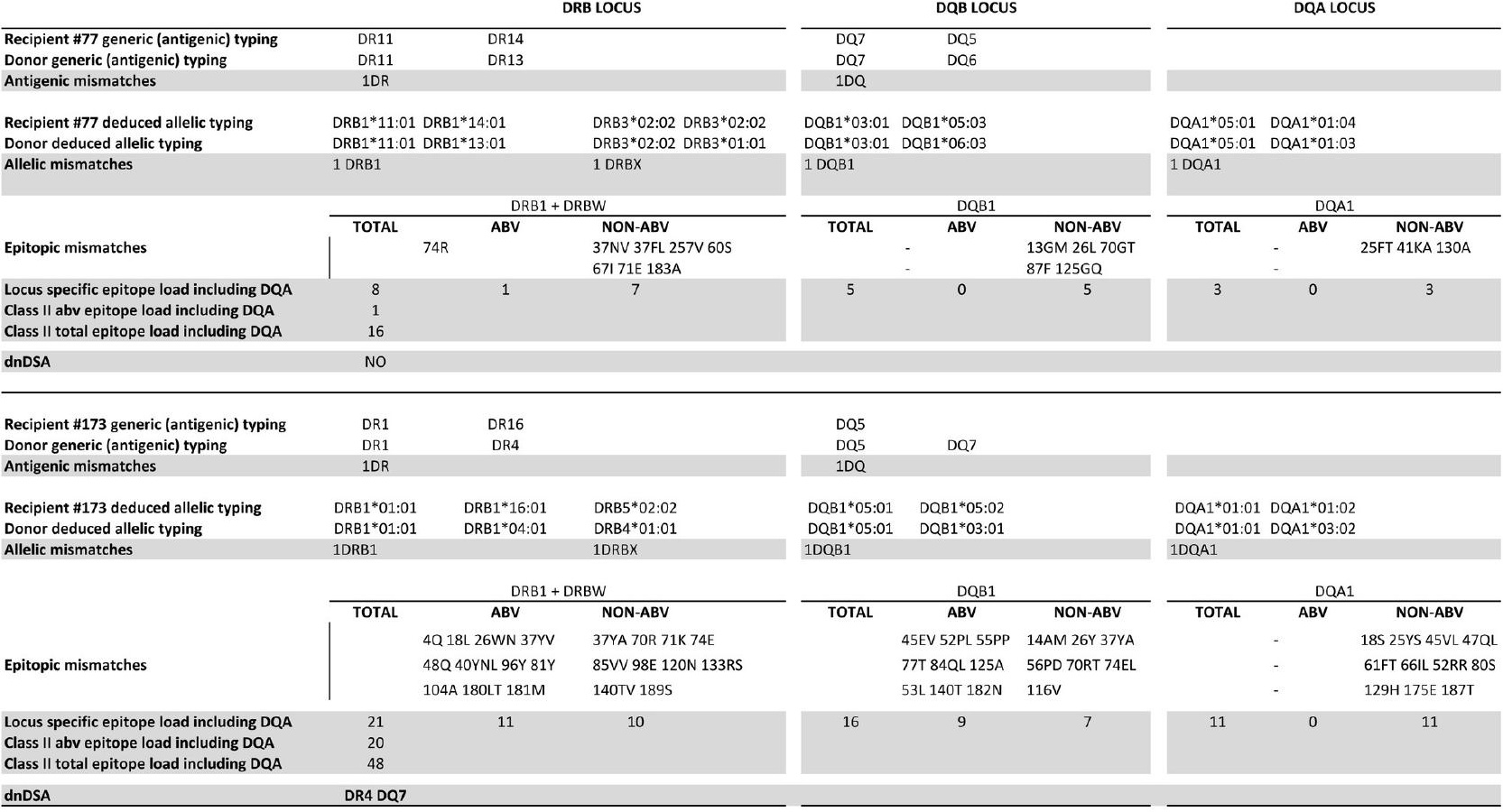


1. DQ7 mismatch seen by recipient \#49 HLA DQ6/DQ9

Top view

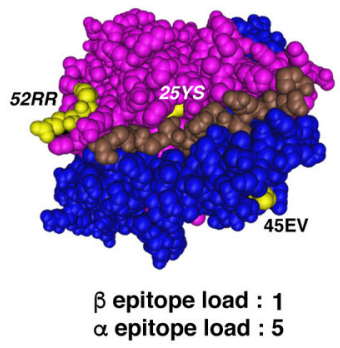

$\beta$ epitope load : 1

$\alpha$ epitope load : 5 $\beta$-chain side view

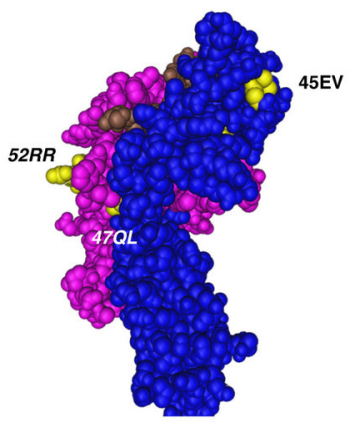

$\alpha$-chain side view

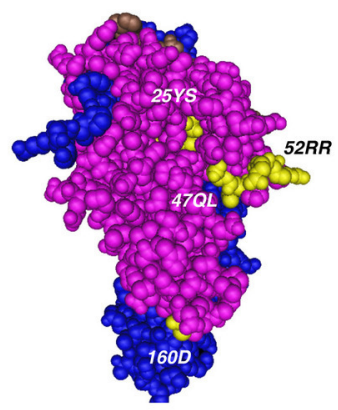

2. DQ7 mismatch seen by recipient \#1 HLA DQ2/DQ4
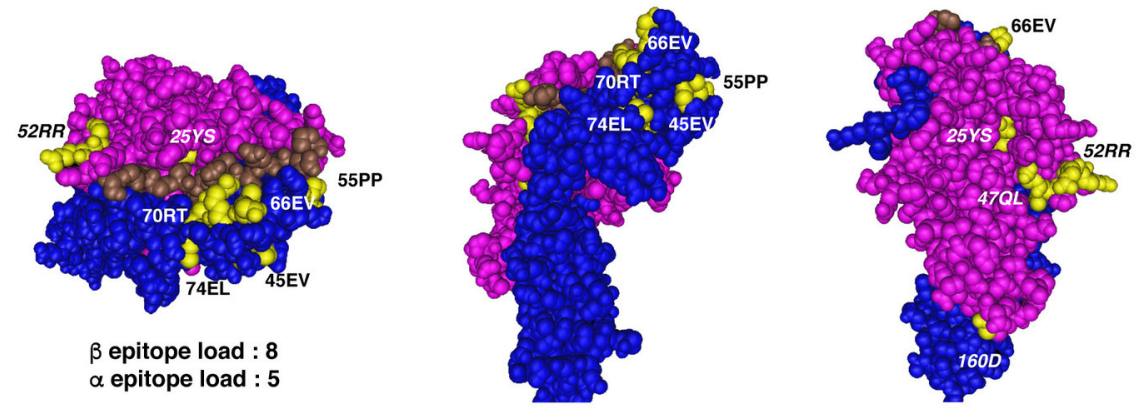

3. DQ7 mismatch seen by recipient \#65 HLA DQ2/DQ2

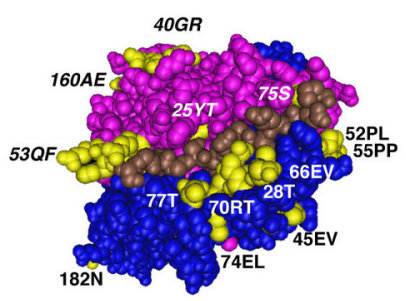

$\beta$ epitope load : 16

$\alpha$ epitope load : 8
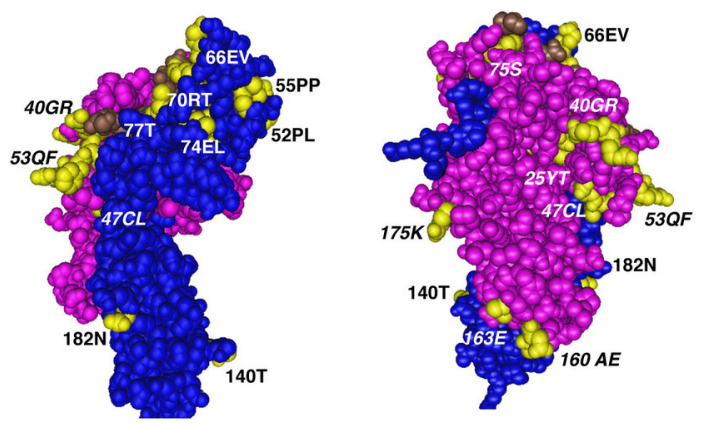


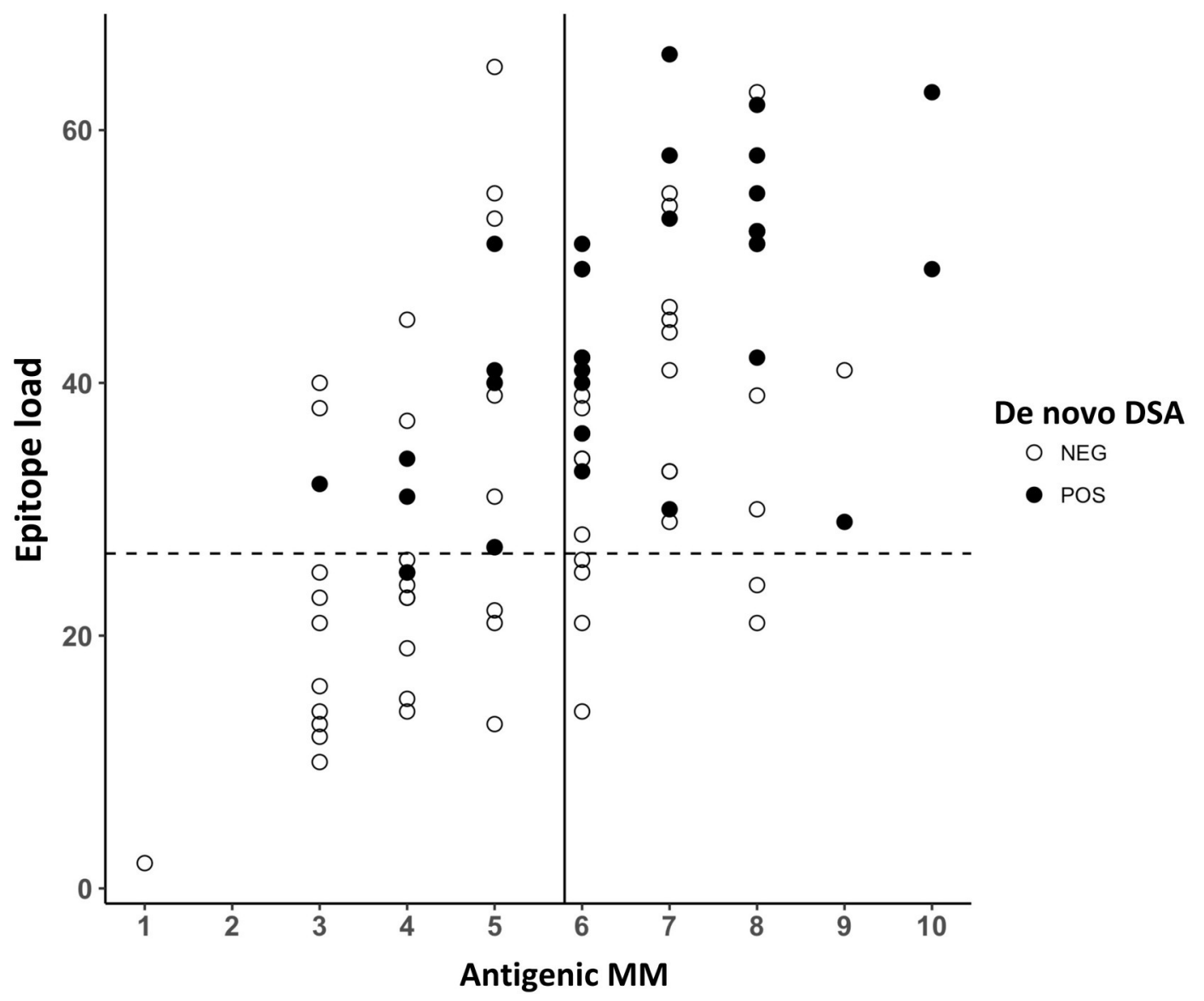




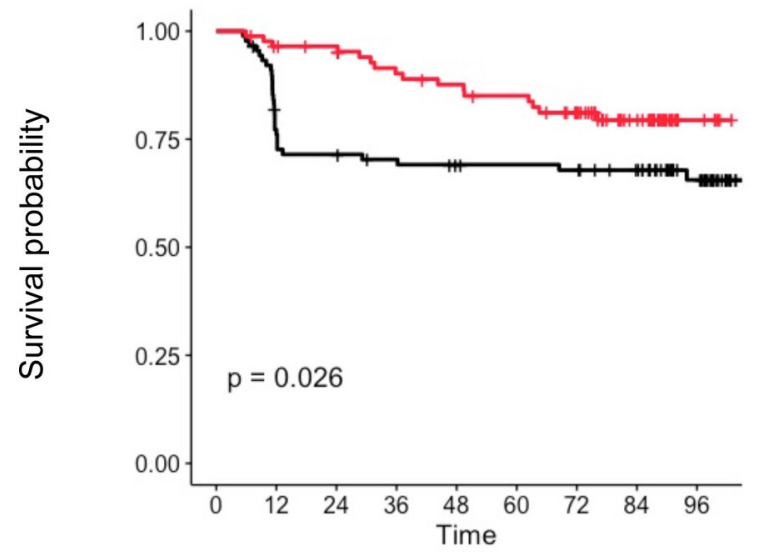

Number at risk

\begin{tabular}{l|ccccccccc} 
everolimus \\
cyclosporine
\end{tabular} \begin{tabular}{ccccccccc}
89 & 67 & 62 & 59 & 55 & 54 & 53 & 48 & 29 \\
86 & 81 & 79 & 71 & 68 & 65 & 57 & 34 & 6 \\
\cline { 2 - 8 } & 12 & 24 & 36 & 48 & 60 & 72 & 84 & 96
\end{tabular}


A DQ7 ${ }^{\text {neg }}$ patients receiving a DQ7 ${ }^{\text {pos }}$ transplant

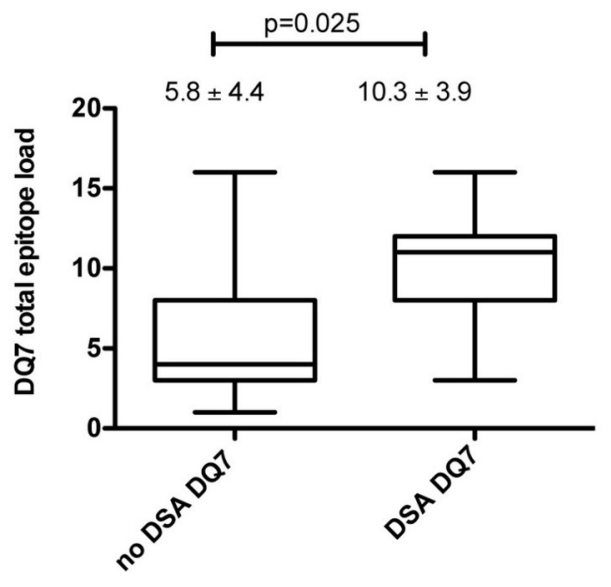

B DQ7 ${ }^{\text {neg }}$ patients receiving a DQ7 ${ }^{\text {pos }}$ transplant

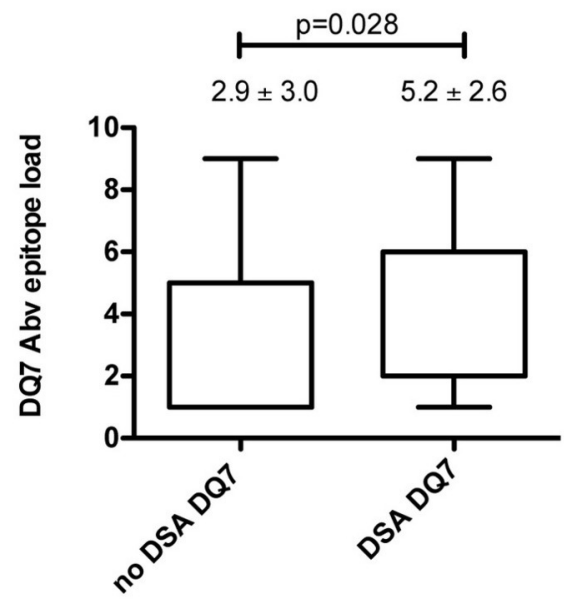

C Mismatched DQ7 epitopes

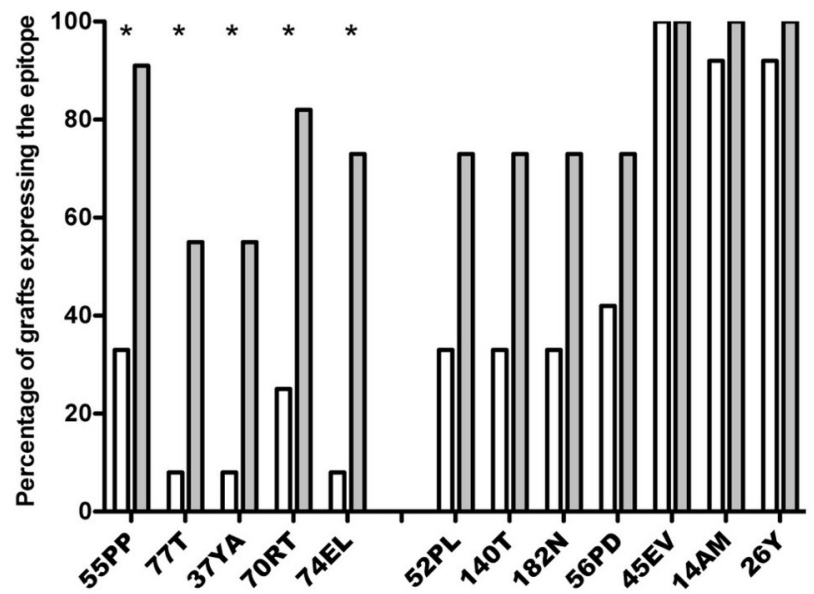

\begin{tabular}{c|ccc}
\hline Epitopes & Odds Ratio & $\mathbf{9 5 \%} \mathbf{C l}$ & $\mathbf{p}$ \\
\hline 55PP & 17,1 & $1.5: 966.4$ & 0.009 \\
77T & 11.6 & $1.0: 657.7$ & 0.27 \\
37 YA & 11.6 & $1.0: 657.7$ & 0.27 \\
70RT & 11.7 & $1.4: 174.4$ & 0.012 \\
74EL & 23.9 & $2.0: 1399.4$ & 0.003 \\
\hline
\end{tabular}

